\title{
Additive Manufacturing Consolidation of Low-Cost Water Atomized Steel Powder Using Micro-Induction Sintering
}

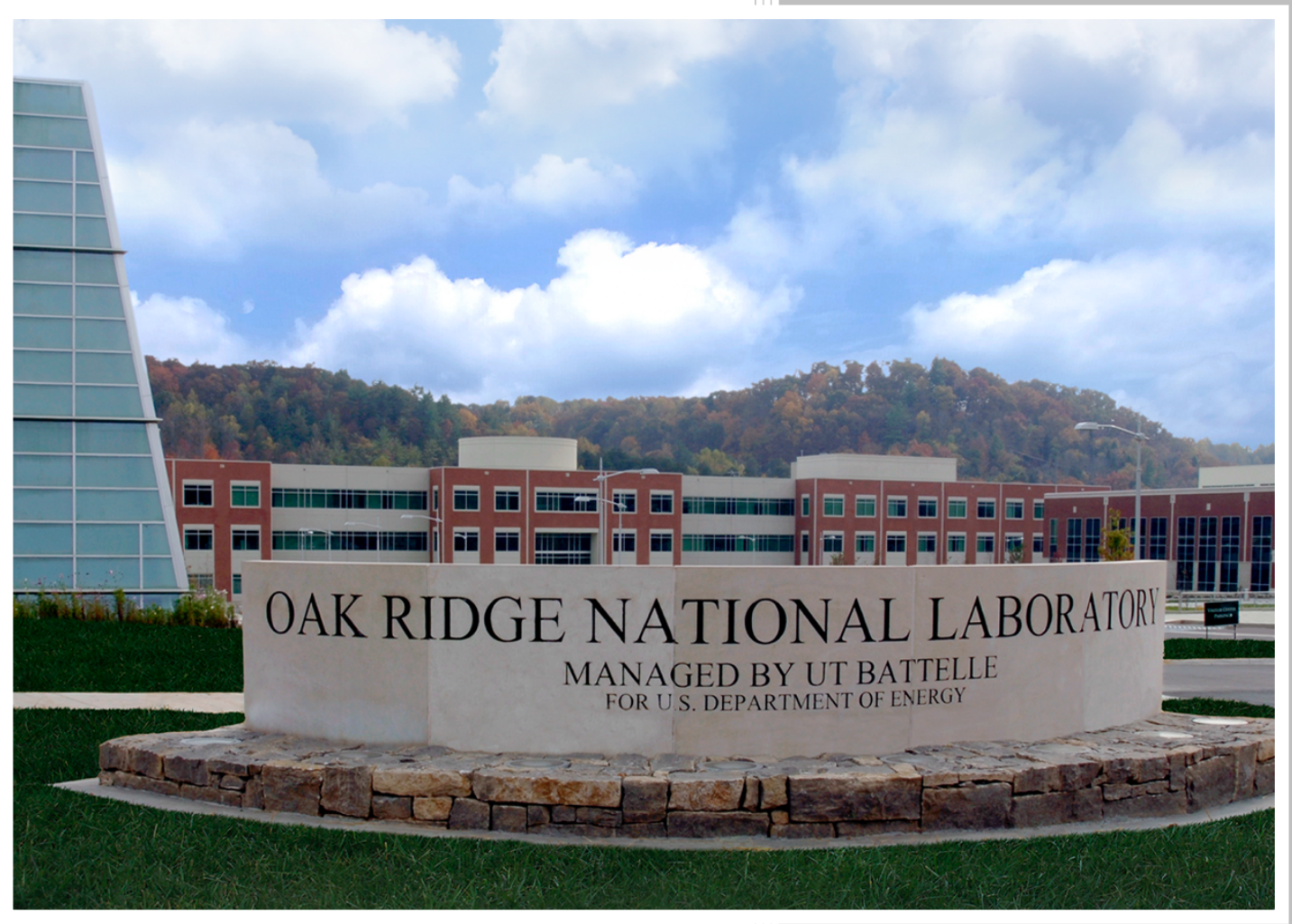

Orlando Rios

April 23, 2018

CRADA FINAL REPORT NFE-15-05758

Approved for Public Release. Distribution is Unlimited. 


\section{DOCUMENT AVAILABILITY}

Reports produced after January 1, 1996, are generally available free via US Department of Energy (DOE) SciTech Connect.

Website http://www.osti.gov/scitech/

Reports produced before January 1, 1996, may be purchased by members of the public from the following source:

National Technical Information Service

5285 Port Royal Road

Springfield, VA 22161

Telephone 703-605-6000 (1-800-553-6847)

TDD 703-487-4639

Fax 703-605-6900

E-mail info@ntis.gov

Website http://www.ntis.gov/help/ordermethods.aspx

Reports are available to DOE employees, DOE contractors, Energy Technology Data Exchange representatives, and International Nuclear Information System representatives from the following source:

Office of Scientific and Technical Information

PO Box 62

Oak Ridge, TN 37831

Telephone 865-576-8401

Fax 865-576-5728

E-mail reports@osti.gov

Website http://www.osti.gov/contact.html

This report was prepared as an account of work sponsored by an agency of the United States Government. Neither the United States Government nor any agency thereof, nor any of their employees, makes any warranty, express or implied, or assumes any legal liability or responsibility for the accuracy, completeness, or usefulness of any information, apparatus, product, or process disclosed, or represents that its use would not infringe privately owned rights. Reference herein to any specific commercial product, process, or service by trade name, trademark, manufacturer, or otherwise, does not necessarily constitute or imply its endorsement, recommendation, or favoring by the United States Government or any agency thereof. The views and opinions of authors expressed herein do not necessarily state or reflect those of the United States Government or any agency thereof. 
ORNL/TM-2018/845

CRADA/ NFE-15-05758

Materials Science and Technology Division

Advanced Manufacturing Office

\title{
Additive Manufacturing Consolidation of Low-Cost Water Atomized Steel Powder Using Micro-Induction Sintering
}

\author{
Authors \\ Orlando Rios \\ William Carter \\ Stefan Ulrich \\ Date Published: \\ April 23, 2018 \\ Prepared by \\ OAK RIDGE NATIONAL LABORATORY \\ Oak Ridge, Tennessee 37831-6283 \\ managed by \\ UT-BATTELLE, LLC \\ for the \\ US DEPARTMENT OF ENERGY \\ under contract DE-AC05-00OR22725
}

Approved For Public Release 


\section{CONTENTS}

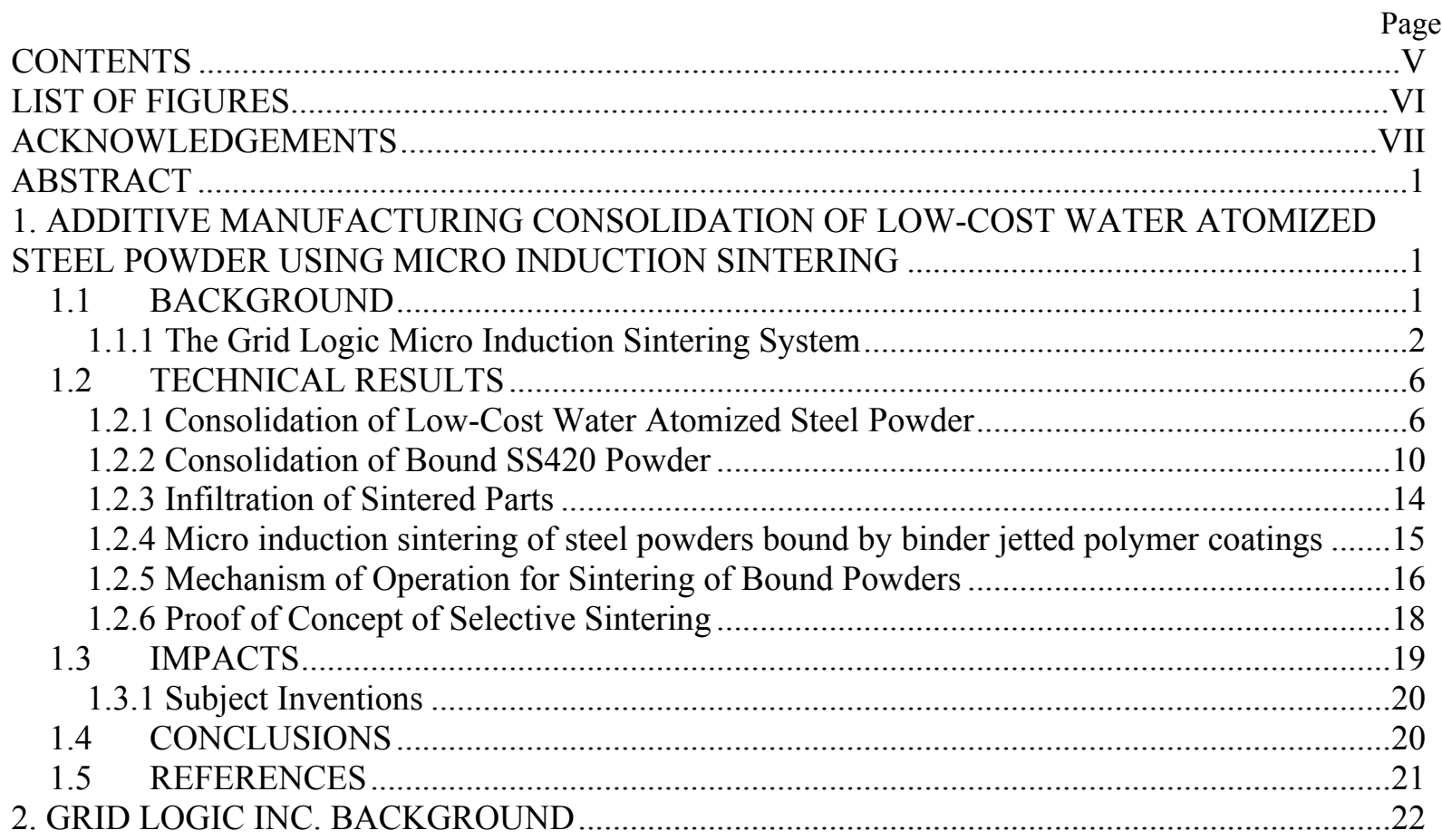




\section{LIST OF FIGURES}

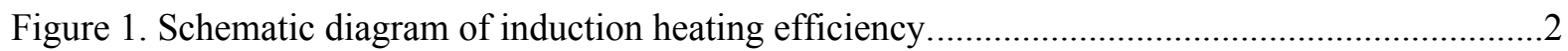

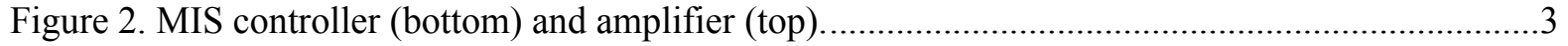

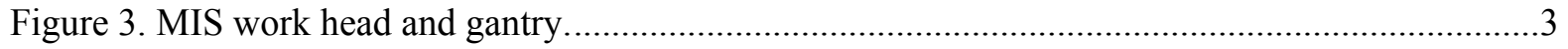

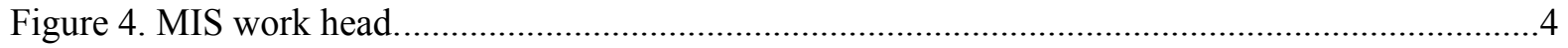

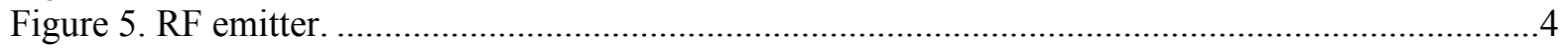

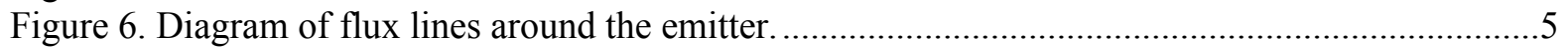

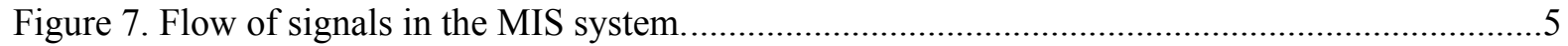

Figure 8. Representation of standing wave created by combined original (forward) signal and

reflected signal [1]. As the forward and reflected signals move along the lines the standing wave changes. The VSWR is the ratio of the highest amplitude of this wave to .........................................6

Figure 9. Low-cost, water-atomized Ancorsteel 1000C powder.....................................................6

Figure 10. Pulse train generated at a power level of $-7 \mathrm{~dB}$ at a frequency of $1245.5 \mathrm{MHz}$...................

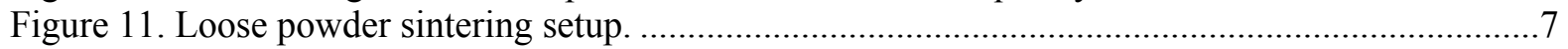

Figure 12. Loosely sintered Ancorsteel 1000C powder..................................................................

Figure 13. Close-up of loosely sintered Ancorsteel 1000C powder...................................................

Table 1. Coupling results with various binders and powders.....................................................

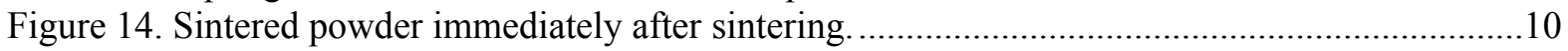

Figure 15. Sintered powder removed from polymer bound disc...................................................10

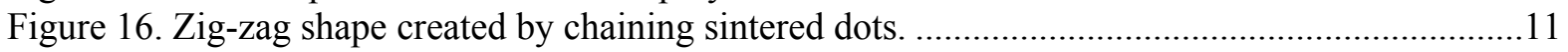

Figure 17. Backscatter SEM images of sintered SS420 powder....................................................11

Figure 18. Leftover binder seen near the edge of a sintered object...................................................11

Figure 19. Several paths attempted with build results, emitter orientation, and arrows showing

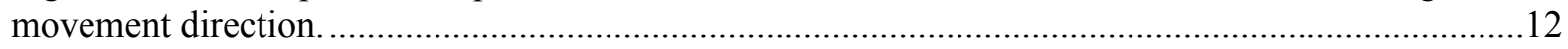

Figure 20. Cross shape built horizontal line first. The upper half of the vertical line didn't sinter due to

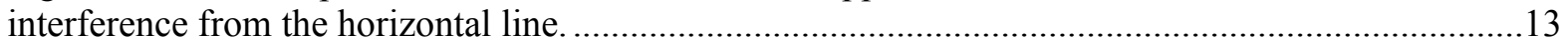

Figure 21. Cross shape built vertical line first. The horizontal line didn't fully sinter due to

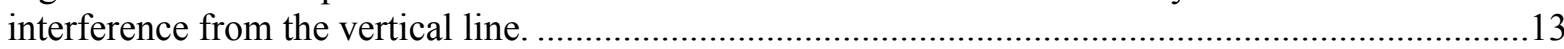

Figure 22. Zig-zag shape built with an upward move direction in the vertical sections. The vertical

sections didn't fully sinter due to interference from previously sintered spots. ..................................13

Figure 23. Zig-zag shape built with a downward move direction in the vertical sections...................14

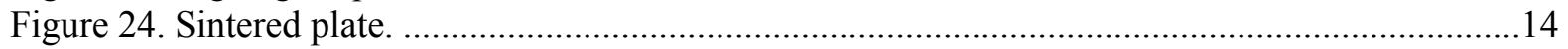

Figure 25. Images of sintered plate after attempted infiltration. .......................................................15

Figure 26. SEM images of sintered plate after attempted infiltration. ................................................15

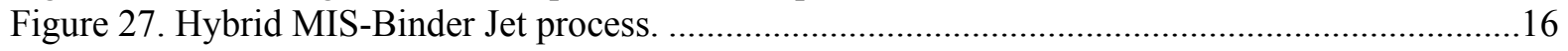

Figure 28. XRD data showing BCC structure for loose powder, FCC structure for sintered powder, and a combination of the two for a ground up piece of a sintered sample.......................................17

Figure 29. The polymer binder keeps the individual particles electrically isolated from one another, this isolation disappears when the binder is decomposed and the particles start heating as a mass

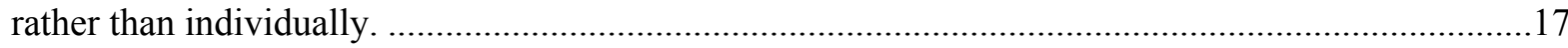

Figure 30. As the material changes from BCC to FCC during heating the skin depth increases. This larger skin depth allows for a larger percentage of the overall mass to be heated...............................18

Figure 31. Proof of concept part designed to simulate the hybrid MIS-Binder Jet process..................18

Figure 32. Proof of concept test result. .........................................................................................19

Figure 33. Sintered part showing fine detail captured where there was a lack of bound powder.........19 


\section{ACKNOWLEDGEMENTS}

This CRADA NFE-15-05758 was conducted as a Technical Collaboration project within the Oak Ridge National Laboratory (ORNL) Manufacturing Demonstration Facility (MDF) sponsored by the US Department of Energy Advanced Manufacturing Office (CPS Agreement Number 24761).

Opportunities for MDF technical collaborations are listed in the announcement "Manufacturing Demonstration Facility Technology Collaborations for US Manufacturers in Advanced

Manufacturing and Materials Technologies" posted at http://web.ornl.gov/sci/manufacturing/docs/FBO-ORNL-MDF-2013-2.pdf. The goal of technical collaborations is to engage industry partners to participate in short-term, collaborative projects within the Manufacturing Demonstration Facility (MDF) to assess applicability and of new energy efficient manufacturing technologies. Research sponsored by the U.S. Department of Energy, Office of Energy Efficiency and Renewable Energy, Advanced Manufacturing Office, under contract DE-AC0500OR22725 with UT-Battelle, LLC. 


\begin{abstract}
ORNL worked with Grid Logic Inc to demonstrate Micro-Induction Sintering (MIS) and binder decomposition of steel powders. It was shown that MIS effectively emits spatially confined electromagnetic energy that is directly coupled to metallic powders resulting in resistive heating of individual particles. The non-uniformity of particle morphology and distribution of the water atomized steel powders resulted in inefficient transfer of energy. It was shown that adhering the particles together using polymer binders resulted in more efficient coupling. Using the MIS processes, debinding and sintering could be done in a single step. When combined with another system, such as binder-jet, this could reduce the amount of required post-processing. An invention disclosure was filed on hybrid systems that use MIS to reduce the amount of required post-processing.
\end{abstract}

\title{
1. ADDITIVE MANUFACTURING CONSOLIDATION OF LOW-COST WATER ATOMIZED STEEL POWDER USING MICRO INDUCTION SINTERING
}

This phase 2 technical collaboration project (MDF-TC-2015-034) was begun on July 17, 2015 and was completed on March 8,2018. The collaboration partner, Grid Logic, Inc. is a small business. Polymer bound steel powders were successfully sintered showing the potential for Micro-Induction Sintering to be combined with other technologies such as binder jet printing to create a system with minimal required post-processing.

\subsection{BACKGROUND}

Grid Logic Inc. is developing a method for sintering and melting fine metallic powders for additive manufacturing using spatially-compact, high-frequency magnetic fields called MicroInduction Sintering (MIS). Phase one of this project modelled the induction heating of fine spherical particles and was conducted as CRADA NFE-14-04983 between Grid Logic and the Oak Ridge National Laboratory (ORNL). One of the challenges in advancing MIS technology for additive manufacturing is in understanding the power transfer to the particles in a powder bed. This knowledge is important to achieving efficient power transfer, control, and selective particle heating during the MIS process needed for commercialization of the technology. The project's phase 1 work provided a rigorous physics-based model for induction heating of fine spherical particles as a function of frequency and particle size. This simulation improved upon Grid Logic's earlier models and provided guidance that will make the MIS technology more effective. The project model was successful and will be incorporated into Grid Logic's power control circuit of the MIS 3D printer product and its diagnostics technology to optimize the sintering process for part quality and energy efficiency.

The goal of this phase 2 project was to use Micro-Induction Sintering to consolidate low-cost water atomized steel powders. This technology enables materials to be sintered in place without the need for additional post processing reducing the number of steps it takes to create a finished part.

Micro-Induction-Sintering is a process that uses concentrated RF radiation to heat and sinter metal powders. The Grid Logic system operates in the $\mathrm{GHz}$ frequency range allowing it to couple to small particles as governed by the skin depth (Fig. 1). The skin depth is defined by the equation

$$
\delta=\sqrt{\frac{2 \rho}{\omega \mu_{r} \mu_{0}}}
$$


where $\delta$ is the skin depth, $\rho$ is the resistivity, $\omega$ is the angular frequency, $\mu_{\mathrm{r}}$ is the relative permeability of the material, and $\mu_{0}$ is the permeability of free space $\left(1.257 \times 10-6 \mathrm{~N} / \mathrm{A}^{2}\right)$. MIS can be used to sinter both loose and polymer bound powders. In the case of polymer bound powders, the process is capable of debinding and sintering in a single step.

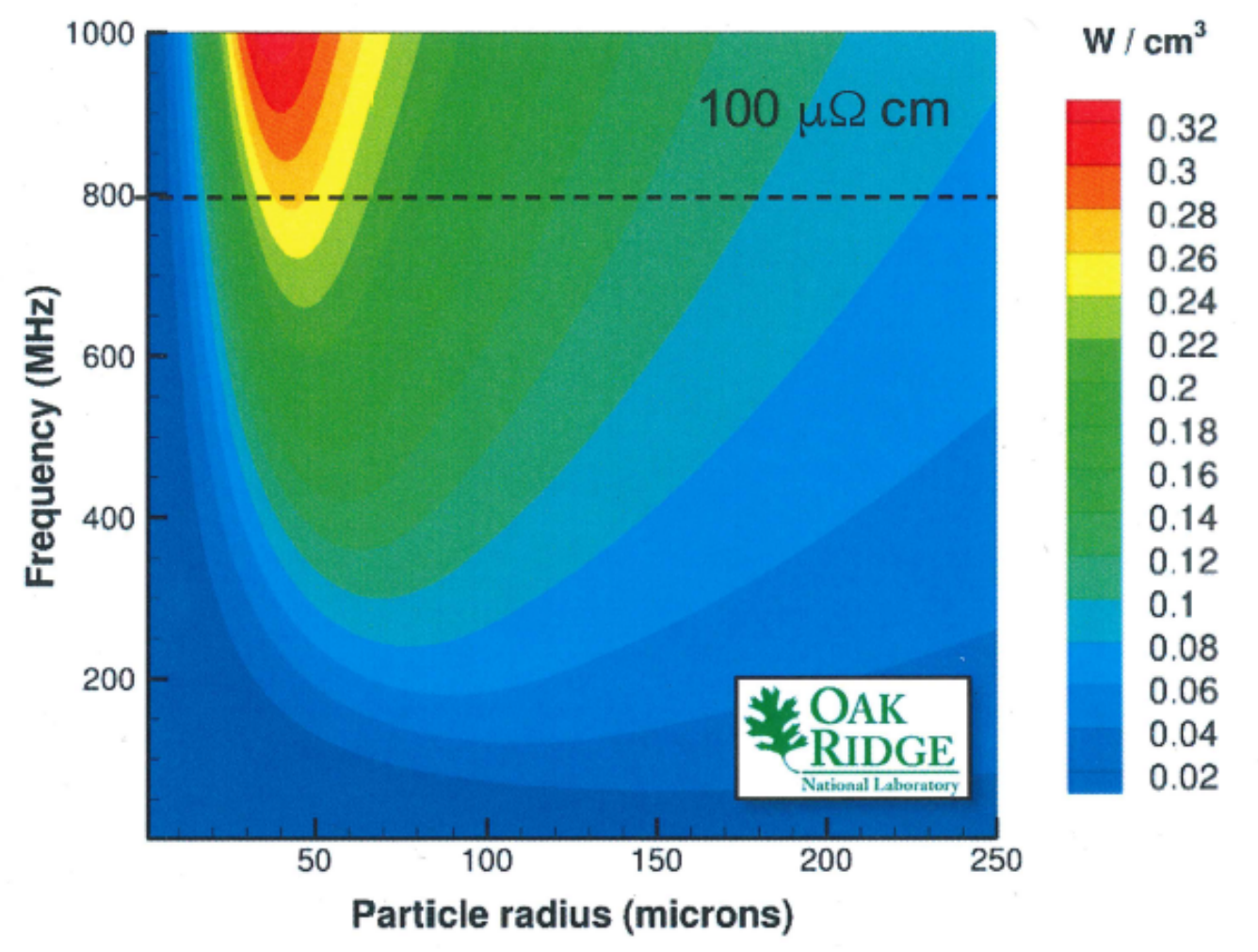

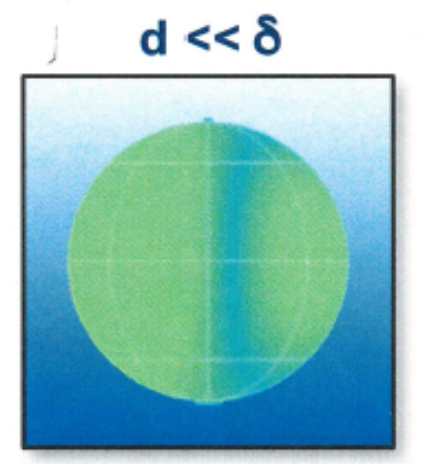

Poor Heating

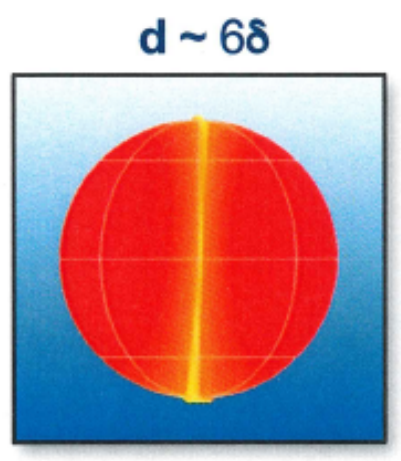

Bulk Heating

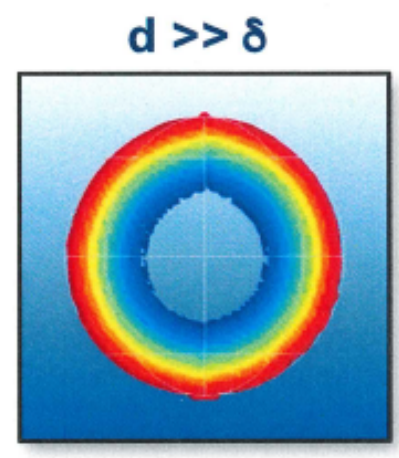

Surface Heating
$\mathrm{A} / \mathrm{mm}^{2}$

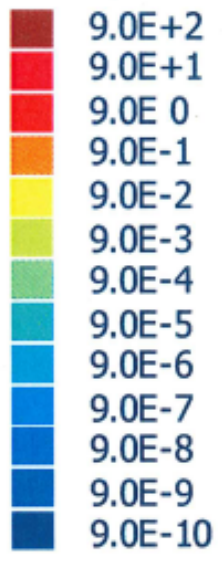

\section{Increasing Frequency}

Figure 1. Schematic diagram of induction heating efficiency.

\subsubsection{The Grid Logic Micro-Induction Sintering System}

The Micro-Induction-Sintering system consists of a gantry, controller, amplifier, and work head. The controller and amplifier are set up outside the glovebox for easy access (Fig. 2). The gantry and work head are inside of a glovebox containing an argon atmosphere in order to prevent oxidation 
(Fig. 3). The glovebox is shielded using copper mesh in order to reduce RF exposure. An RF survey showed that, with this mesh installed, the exposure at maximum power is less than $0.5 \%$ of the allowable limit, the smallest measurable value. Without it the exposure was around $2.5 \%$ of the allowable limit meaning that the system can be safely operated without the mesh in place. The work head is mounted to the gantry and is cooled using an external chiller supplying $25^{\circ} \mathrm{C}$ water. The existing waterlines that provide the glovebox's furnace with cooling water were modified to supply water to the MIS work head.

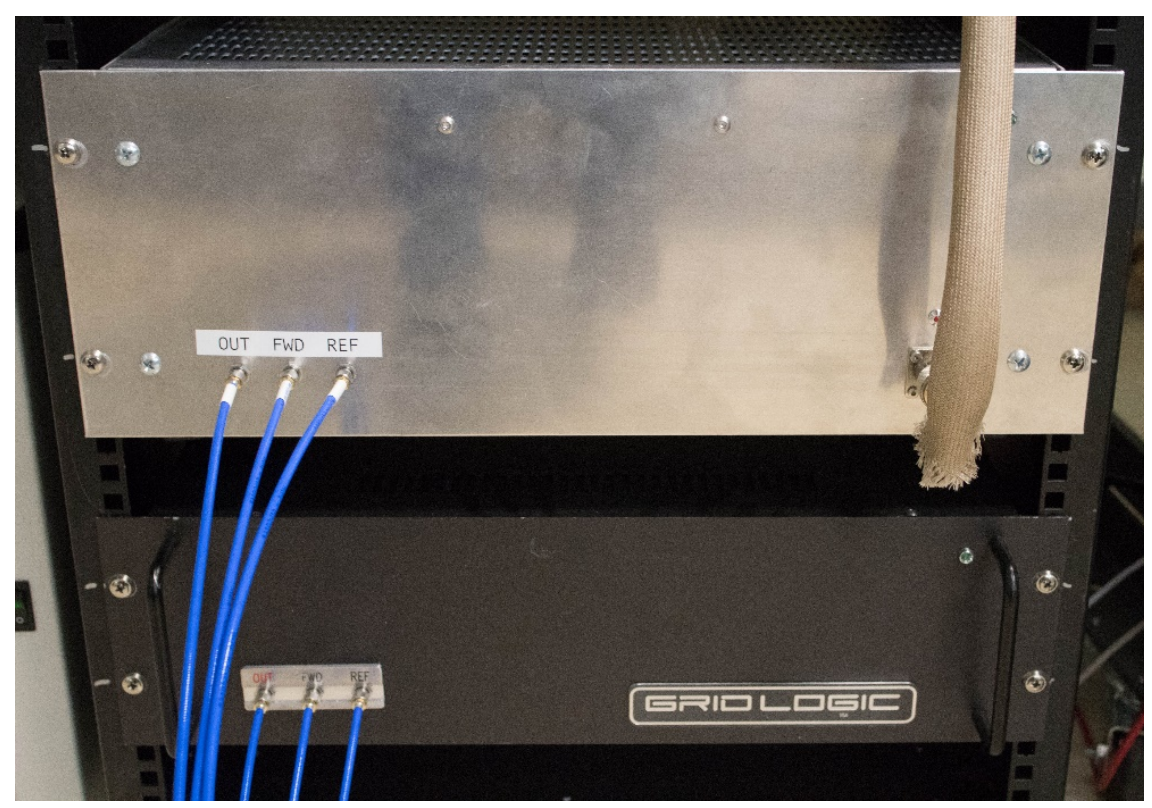

Figure 2. MIS controller (bottom) and amplifier (top).

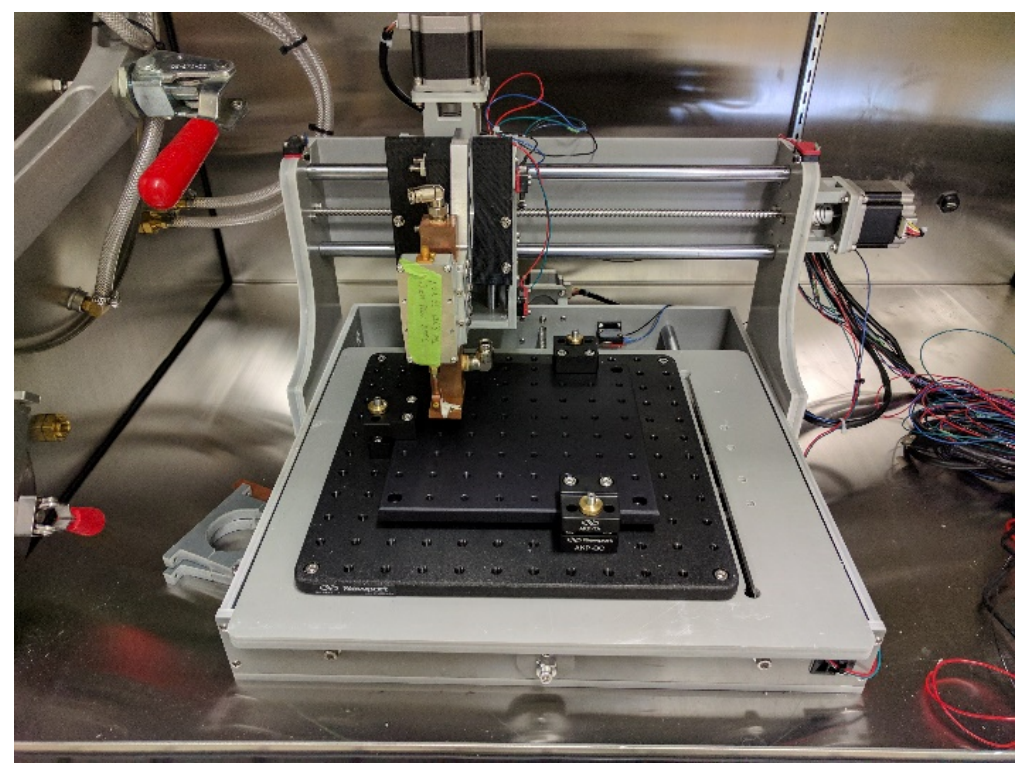

Figure 3. MIS work head and gantry.

The controller generates low power RF signals and processes returned signals from the amplifier. If the returned signals show that the system isn't properly tuned the controller will stop signal generation in order to prevent damage to the equipment. The amplifier receives low power RF signals 
from the controller, amplifies them to power levels that are capable of heating metals to the point of sintering, and returns signals corresponding to the coupling quality to the controller. The system is controlled from a computer running proprietary software. This computer is also used to control the gantry system using open source computer numeric control (CNC) software.

The work head (Fig. 4) consists of a tuned waveguide and an emitter. The waveguide can be tuned to allow the system to couple to specific powders. The work head used for these experiments was tuned for Ancorsteel 1000C, a low-cost, water atomized, stainless steel powder. The emitter consists of a small copper block with a small hole and a slot cut into it (Fig. 5). The RF signal is concentrated at the exit of the hole (Fig. 6).

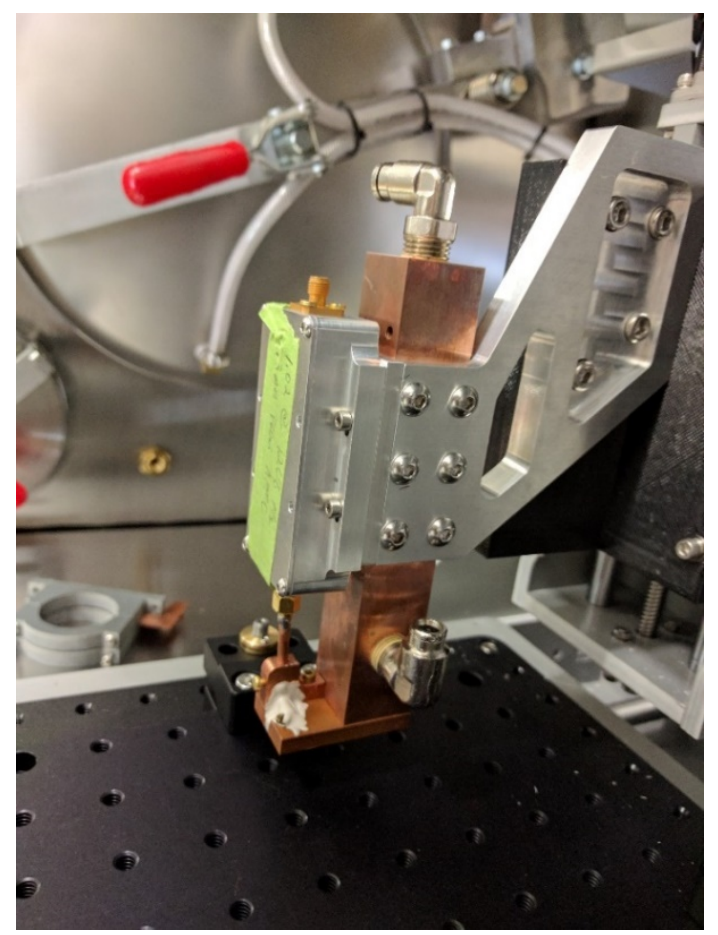

Figure 4. MIS work head.

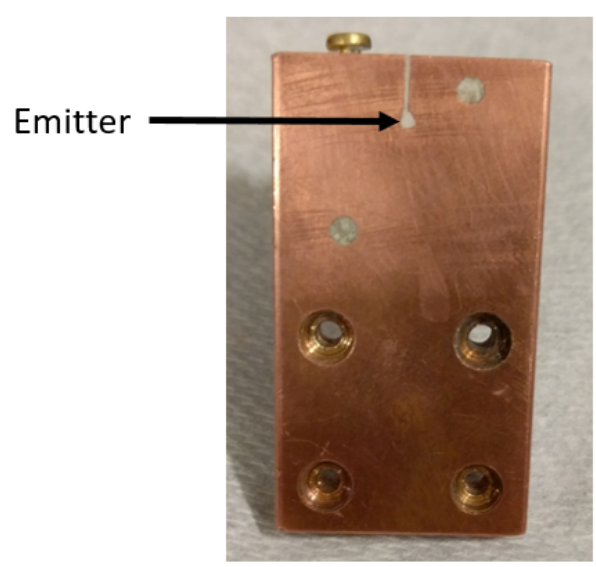

Figure 5. RF emitter. 


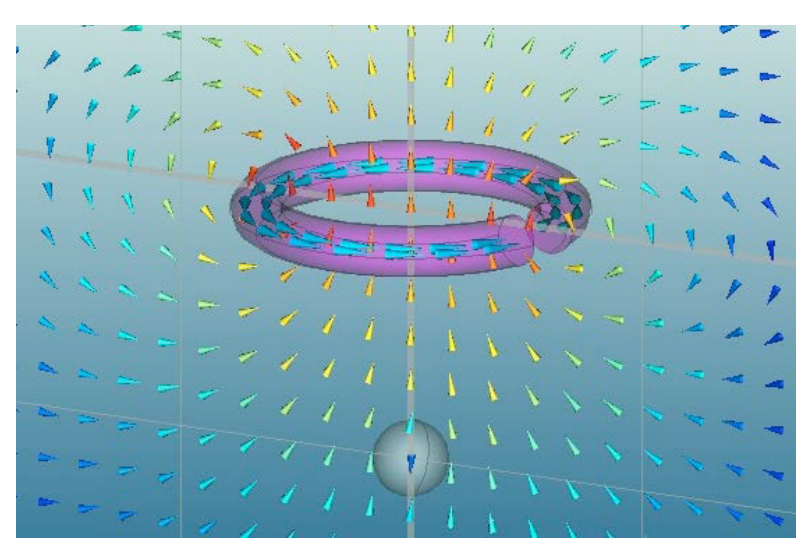

Figure 6. Diagram of flux lines around the emitter.

When the system is triggered the controller sends a low-power RF signal to the amplifier. The amplifier then amplifies this signal to a level that is able to heat the powder (usually $>200 \mathrm{~W}$ ) and sends it to the workhead. The signal is transmitted out of the emitter and some of the power is reflected back (Fig. 7). The amplifier reports the levels of the forward and reflected power to the controller which uses them to determine the voltage standing wave ratio (VSWR) and evaluate the coupling. The VSWR is the ratio of the peak amplitude of the standing wave resulting from the combination of the forward signal and the reflected signal to the minimum amplitude (Fig. 8). The higher the VSWR the less power is transmitted to the sample. The lowest possible VSWR value is one.

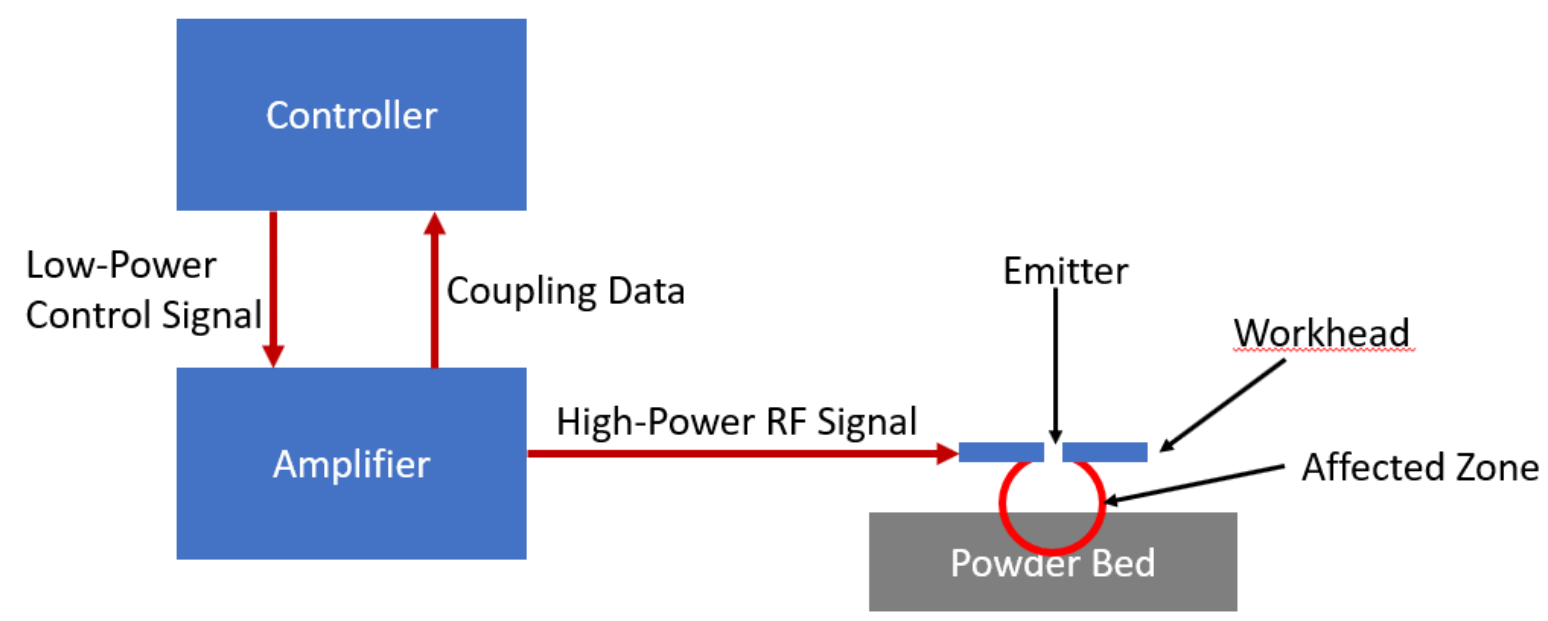

Figure 7. Flow of signals in the MIS system. 


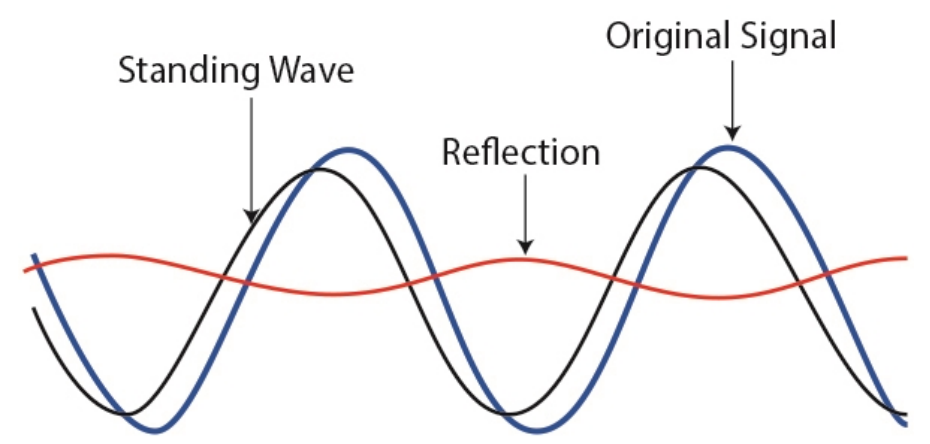

Figure 8. Representation of standing wave created by combined original (forward) signal and reflected signal [1]. As the forward and reflected signals move along the lines the standing wave changes.

\subsection{TECHNICAL RESULTS}

\subsubsection{Consolidation of Low-Cost Water Atomized Steel Powder}

Several unbound, low-cost, water atomized powders, including Ancorsteel 1000B, Ancorsteel $1000 \mathrm{C}$, and R5605, were tested at various power levels and using multiple combinations of settings. It was found that Ancorsteel 1000C, a low-cost, water atomized, stainless steel powder, (Fig. 9) coupled best. Ancorsteel 1000C is a low-oxygen, low-nitrogen, water atomized steel powder designed for electromagnetic applications.

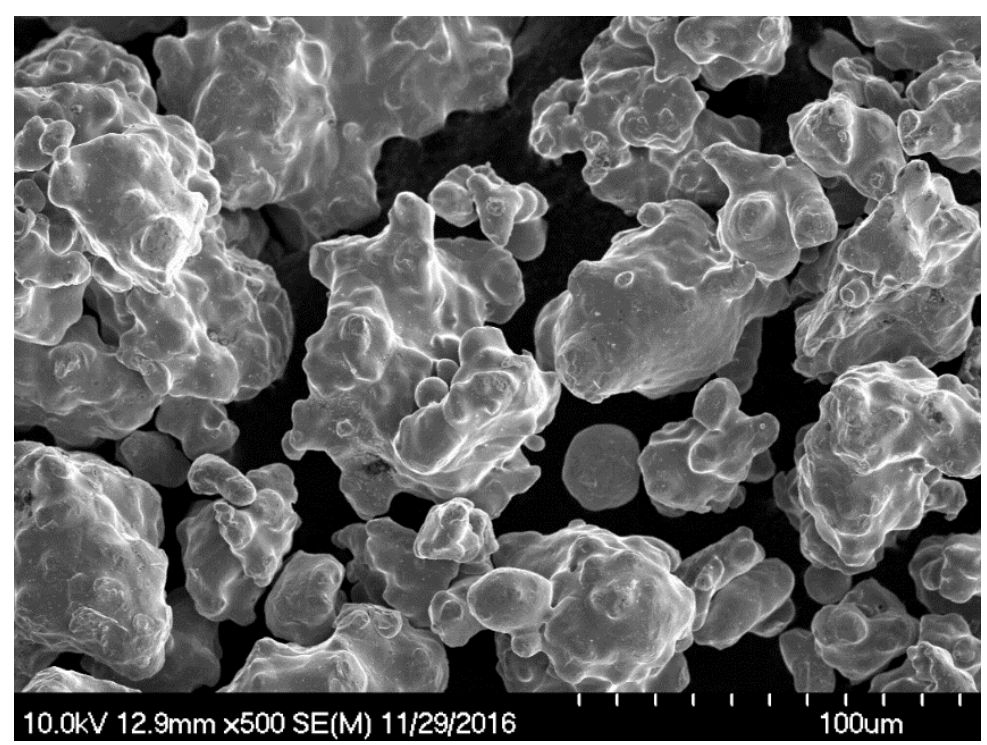

Figure 9. Low-cost, water-atomized Ancorsteel 1000C powder.

Unbound powders processed using MIS in air created loosely bound samples that fell apart as soon as they were touched or moved for analysis (Figures 10 and 11). Testing was continued in an argon atmosphere. Loose Ancorsteel 1000C powder was successfully sintered, however, the dots created by the sintering process were too loosely sintered for any analysis (Figures 12 and 13). 


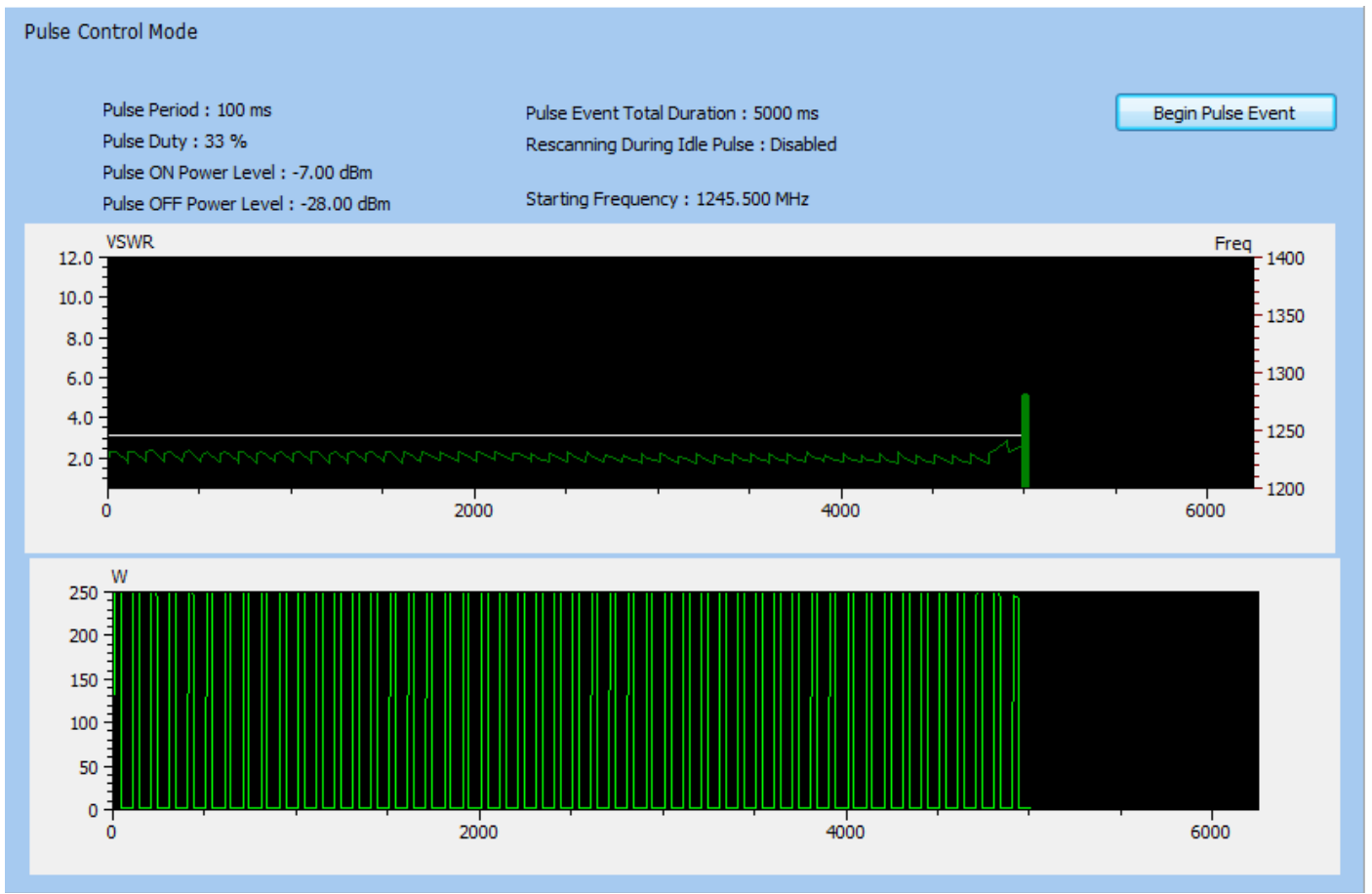

Figure 10. Pulse train generated at a power level of $-7 \mathrm{~dB}$ at a frequency of $1245.5 \mathrm{MHz}$.

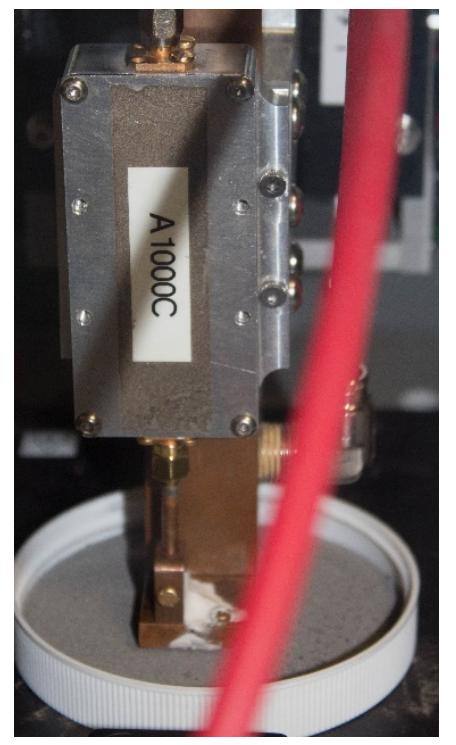

Figure 11. Loose powder sintering setup. 


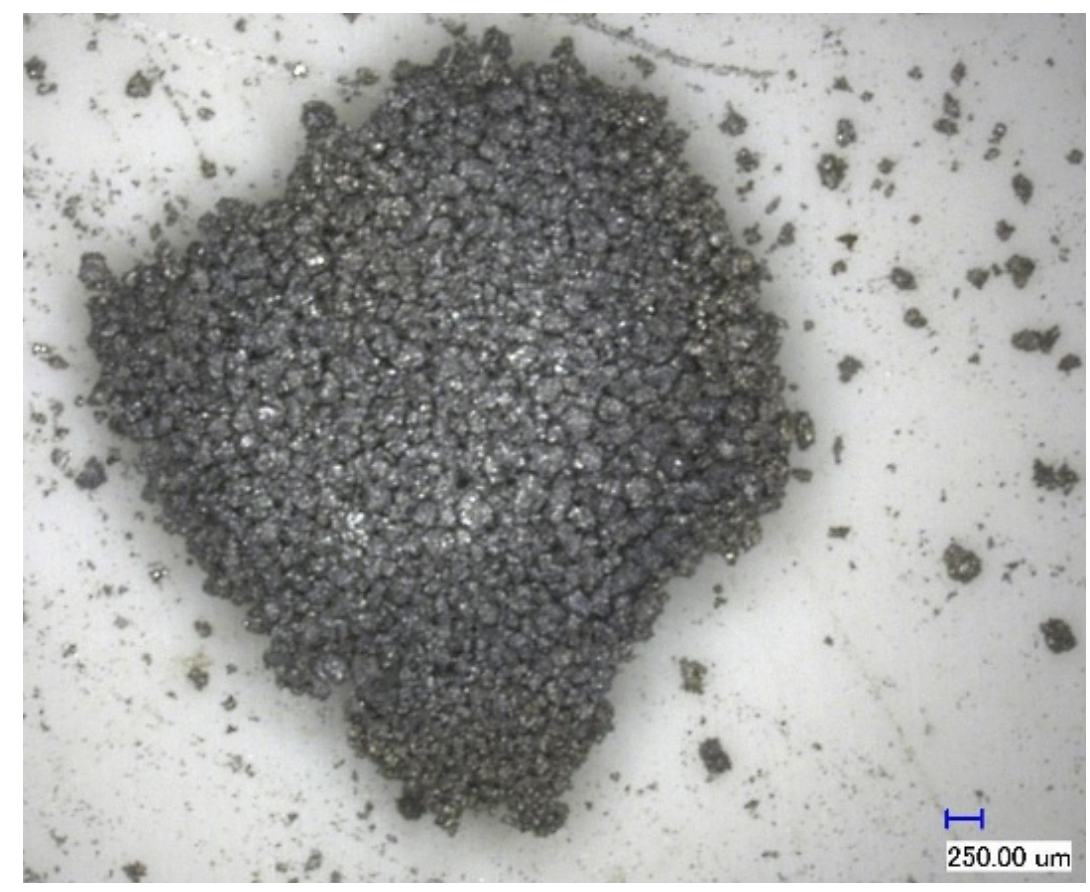

Figure 12. Loosely sintered Ancorsteel 1000C powder.

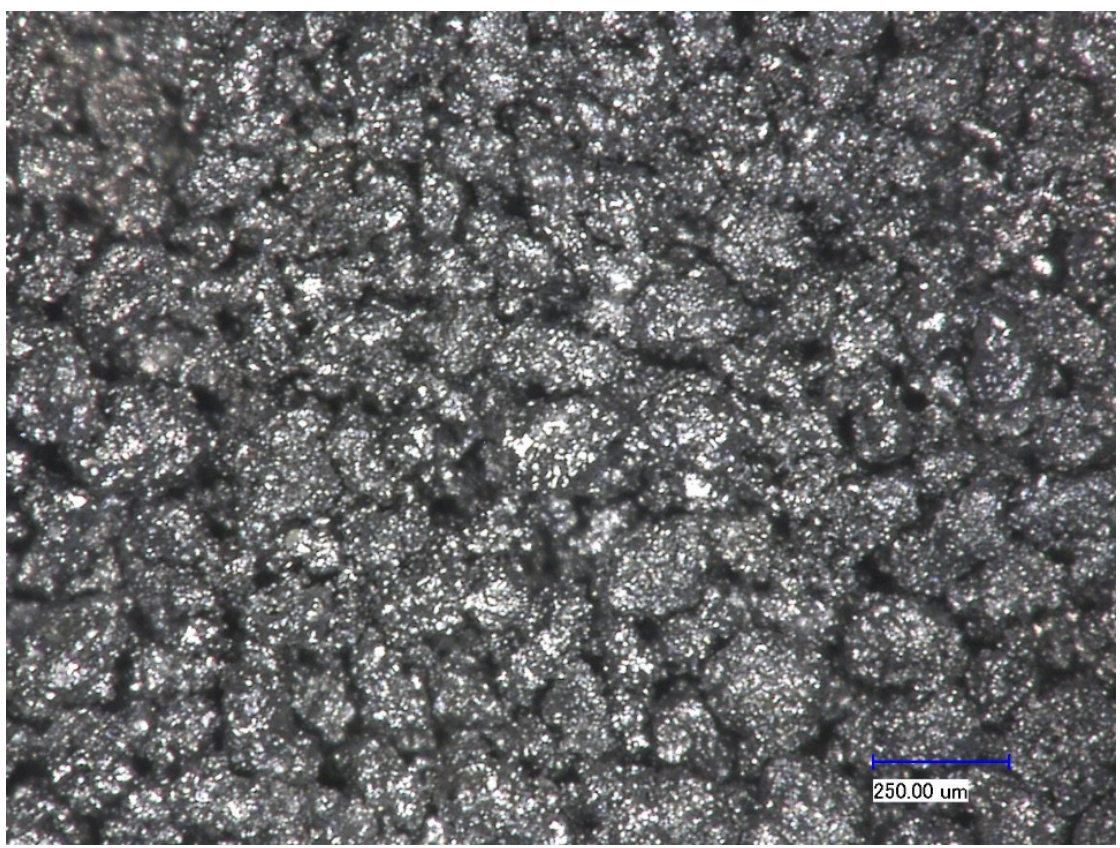

Figure 13. Close-up of loosely sintered Ancorsteel 1000C powder.

Additionally, loose $44 \mu \mathrm{m}$ SS420 powder was exposed to RF using the work head tuned for Ancorsteel 1000C. This powder is a higher cost, gas atomized powder with higher sphericity and more uniform particle size and is designed for additive manufacturing purposes. Both single step and multistep processes were attempted but nothing more than discoloring and possible loose sintering was observed. Any sintering that may have occurred was loose enough that the parts were unable to be removed from the powder without crumbling. 
Around 50 experiments were run with unbound powder without strong sintering. It was suspected that movement of the powder could be interfering with the sintering process. In order to combat this movement the powders were bound using polymers. The water atomized powders were bound by mixing them with a polymer binder dissolved in a solvent then letting the solvent evaporate leaving a bound powder disc. The SS420 powder was bound using a binder jet printing system.

Three binders were tested, polypropylene carbonate (PPC), polyethylene glycol (PEG) and polyvinylpyrrolidone. It was found that polypropylene carbonate bound Ancorsteel 1000C coupled best among the water atomized powders. (Table 1)

Table 1. Coupling results with various binders and powders.

\begin{tabular}{|l|l|l|}
\hline Powder & Binder & Coupling? \\
\hline A1000B & None & Y \\
\hline A1000B & PPC & N \\
\hline A1000B & PEG & N \\
\hline A1000B & PVP & N \\
\hline A1000C & None & Y \\
\hline A1000C & PPC & Y \\
\hline A1000C & PEG & N \\
\hline A1000C & PVP & N \\
\hline R5605 & None & N \\
\hline R5605 & PPC & N \\
\hline R5605 & PEG & N \\
\hline R5605 & PVP & N \\
\hline
\end{tabular}

Bound powders processed using MIS in air experienced binder decomposition but left holes without sintering or consolidation. It is suspected that the vaporizing binder carried away the powder leaving nothing to sinter. SEM images of the processed bound powder discs showed no signs of sintering or consolidation.

Testing was continued in an argon atmosphere. When sintering was attempted, any power level high enough to sinter resulted in empty holes in the samples indicating that the powder was still being carried away during the binder decomposition process rather than being sintered. It was found that the powder could be left in the hole if a long, low power pulse cycle was used. However, this powder remained loose with no signs of sintering or consolidation. A higher power pulse cycle after this could loosely sinter some of the powder, but in a very irregular shape.

A two-stage sintering process was used to avoid the powder being carried away by the vaporizing binder. First a long, low power pulse $(\approx 100 \mathrm{~W})$ was used to gently decompose the binder. Then a short, high power pulse $(\approx 200 \mathrm{~W})$ was used to sinter the loose powder. This process resulted in loosely sintered, irregular shapes (Figures 14 and 15). 


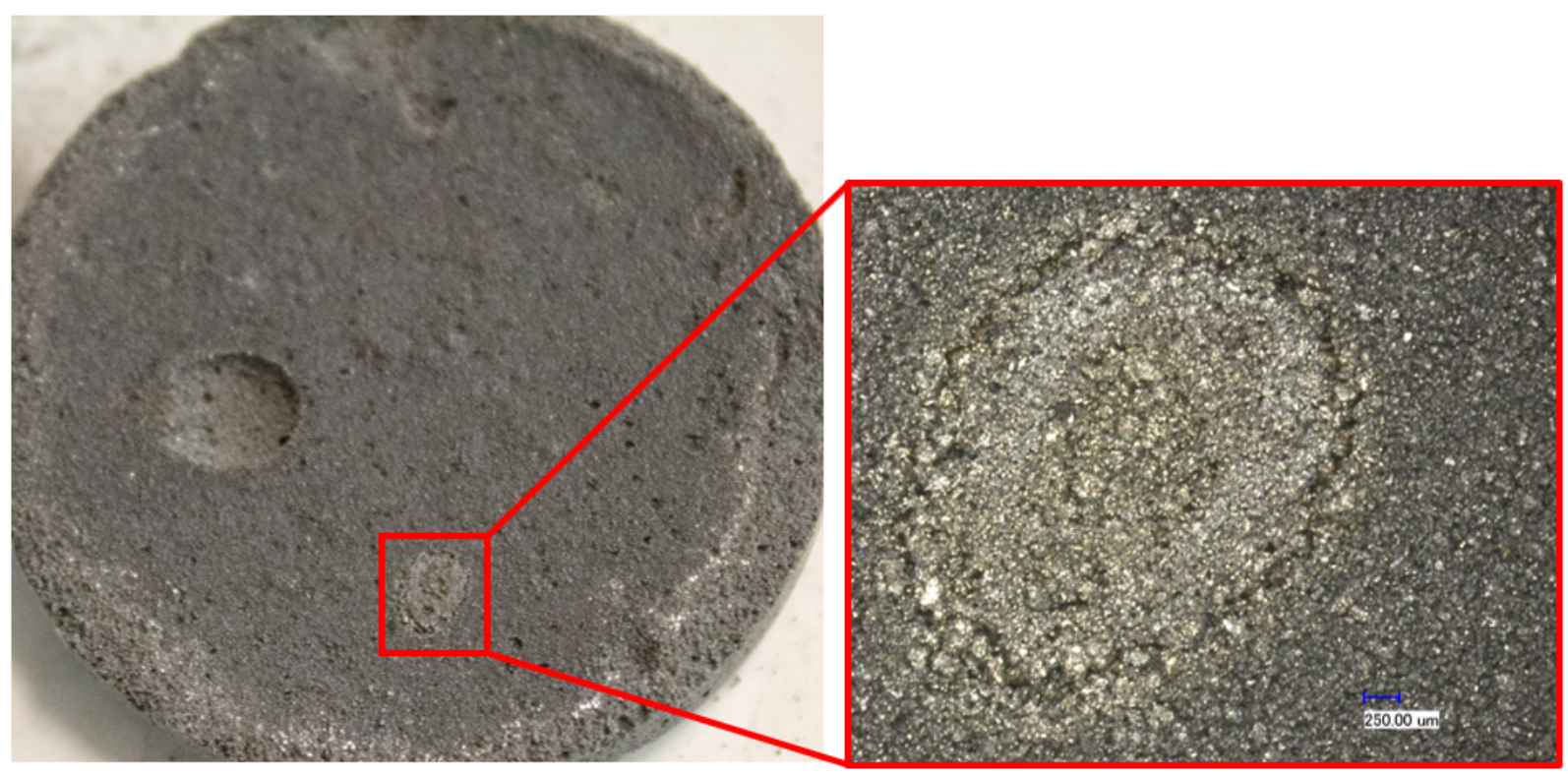

Figure 14. Sintered powder immediately after sintering.

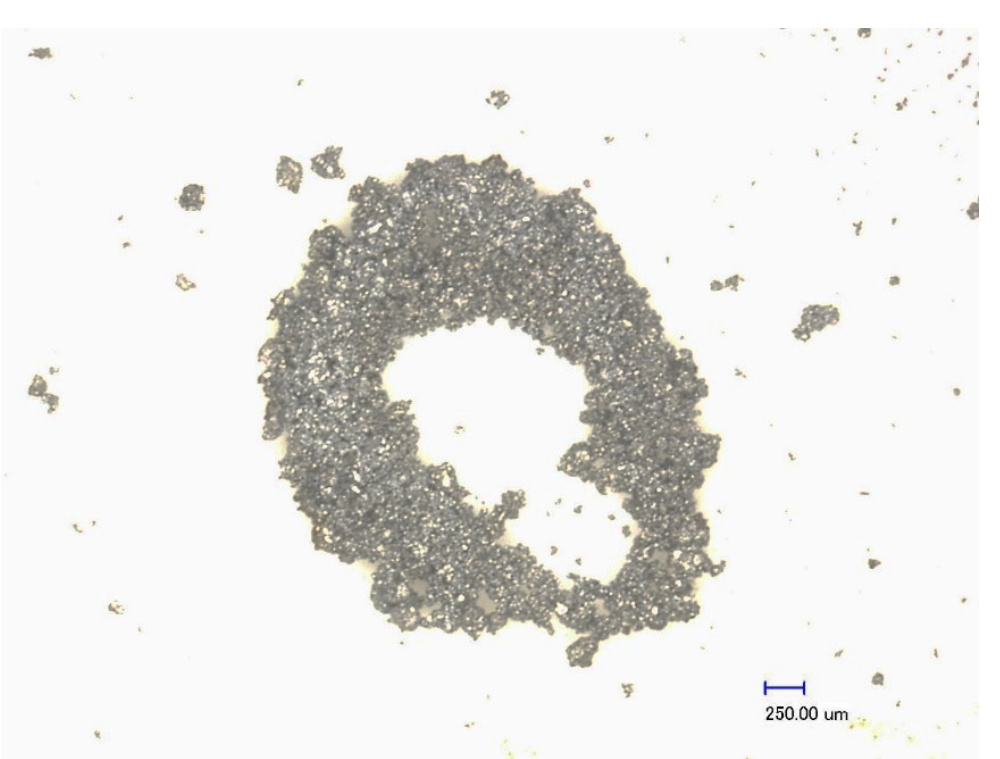

Figure 15. Sintered powder removed from polymer bound disc.

\subsubsection{Consolidation of Bound SS420 Powder}

Polymer bound SS420 alloy powder was used for additional sintering tests. Unlike the low-cost Ancorsteel $1000 \mathrm{C}$ powder, this powder is gas atomized making it highly spherical and uniform. The powder used for these experiments had a particle size of around $44 \mu \mathrm{m}$. Sintering was done using the same procedure as with the bound Ancorsteel $1000 \mathrm{C}$ powder. This resulted in well sintered parts that could be handled without breaking. Additionally, some melting was observed. After sintering was done with a multi-step process similar to that used for the bound Ancorsteel 1000C, it was discovered that the same results could be obtained using a single step process. Larger parts were created by sintering a dot, moving the work head, sintering a connecting dot, and repeating until the desired part shape was created (Figures 16-18). 


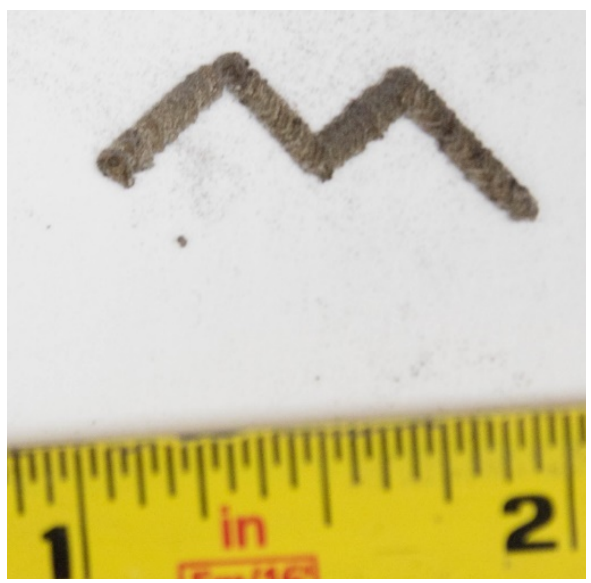

Figure 16. Zig-zag shape created by chaining sintered dots.

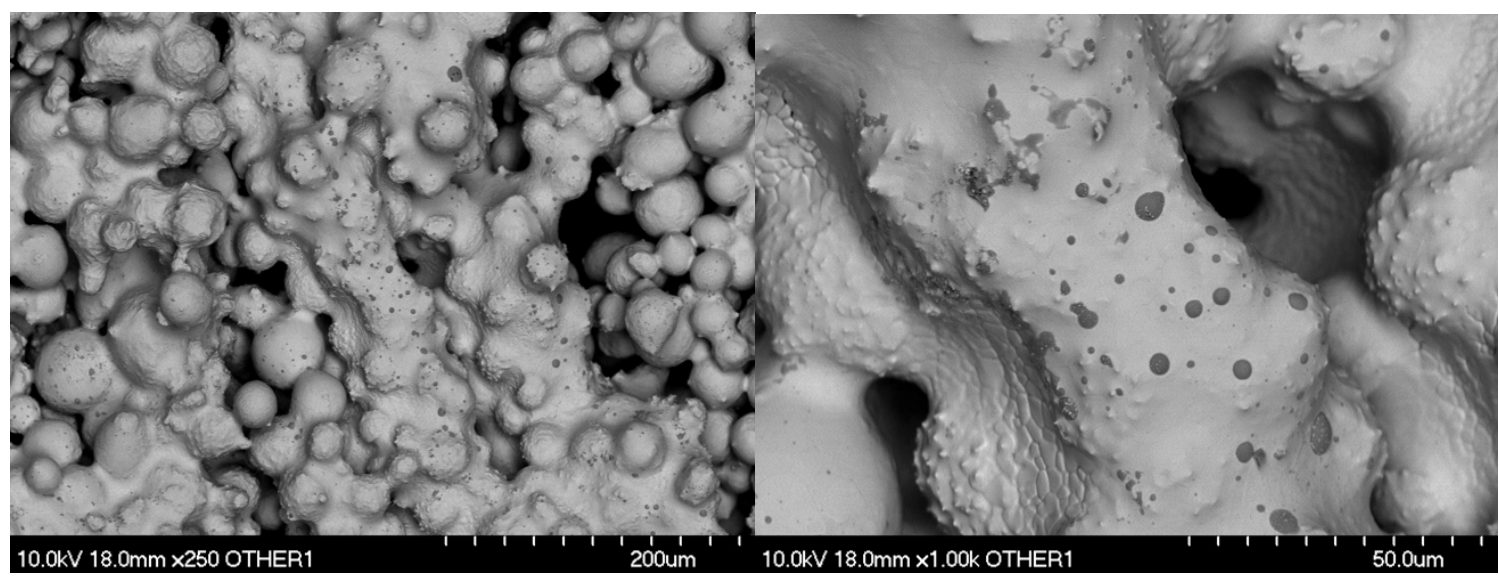

Figure 17. Backscatter SEM images of sintered SS420 powder.

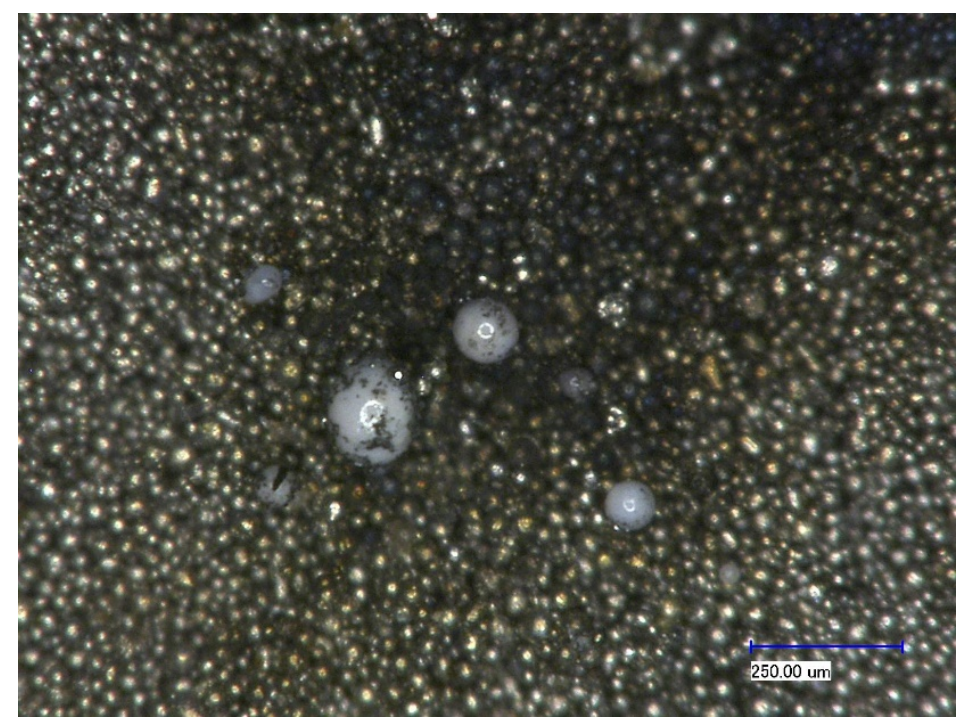

Figure 18. Leftover binder seen near the edge of a sintered object.

An investigation into the limitations of the system was carried out by attempting to sinter several 
shapes and looking at the resulting builds (Fig. 19). It was discovered that the position of previously sintered material relative to the emitter plays a large role in determining if a spot will sinter. Any sintered material under the hole or slot in the emitter interferes with coupling and will completely prevent sintering and even debinding. Additionally, sintered material near the hole or slot can interfere with sintering leading to either loose sintering or just debinding without sintering (Figures 20-23). This interference is caused by changes in the capacitance affecting the way the work head couples to the material. Changes in coupling can lead to inefficient energy transfer meaning that much of the energy from the RF signal is lost without being transferred to the material.
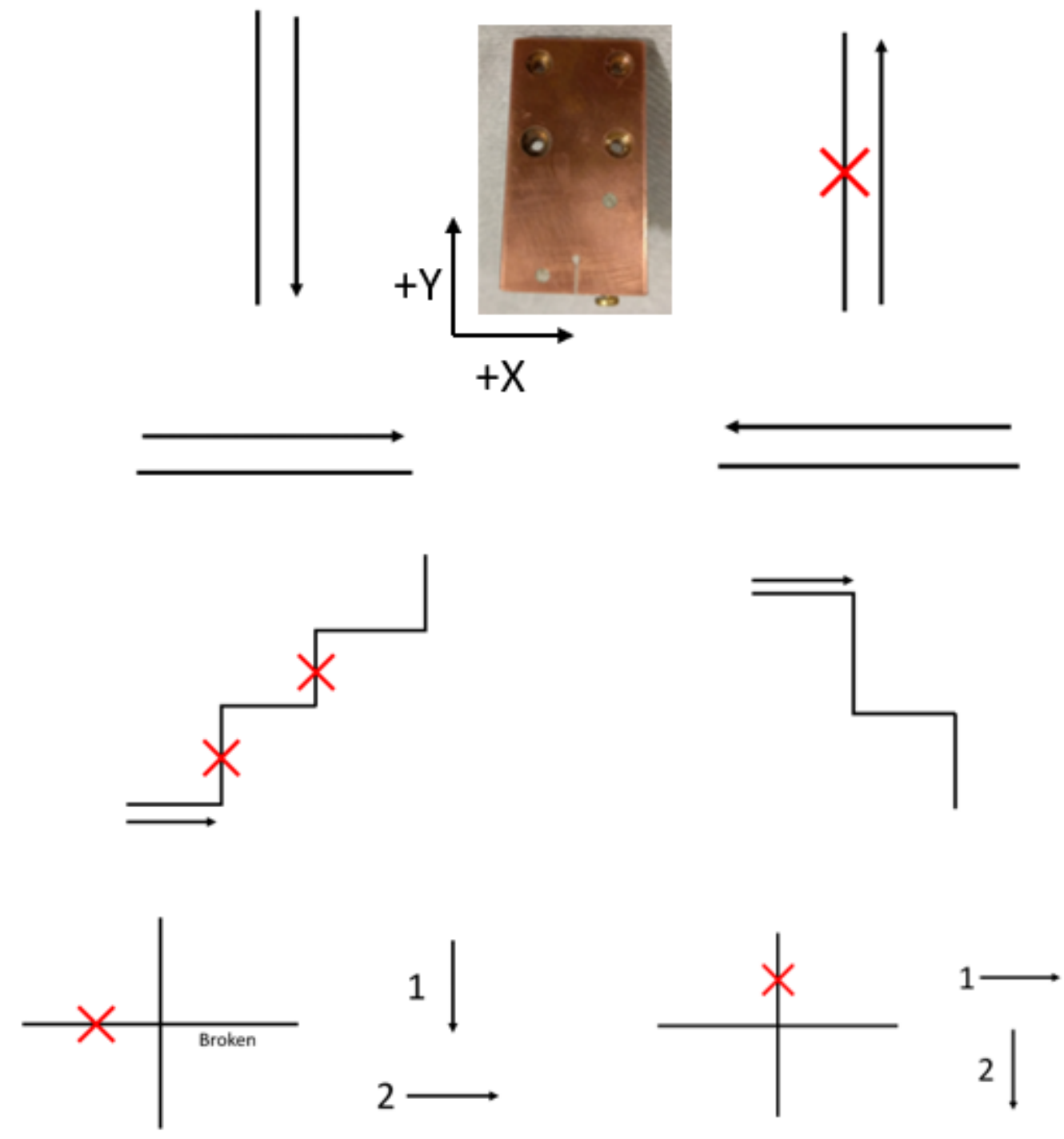

Figure 19. Several paths attempted with build results, emitter orientation, and arrows showing movement direction. 


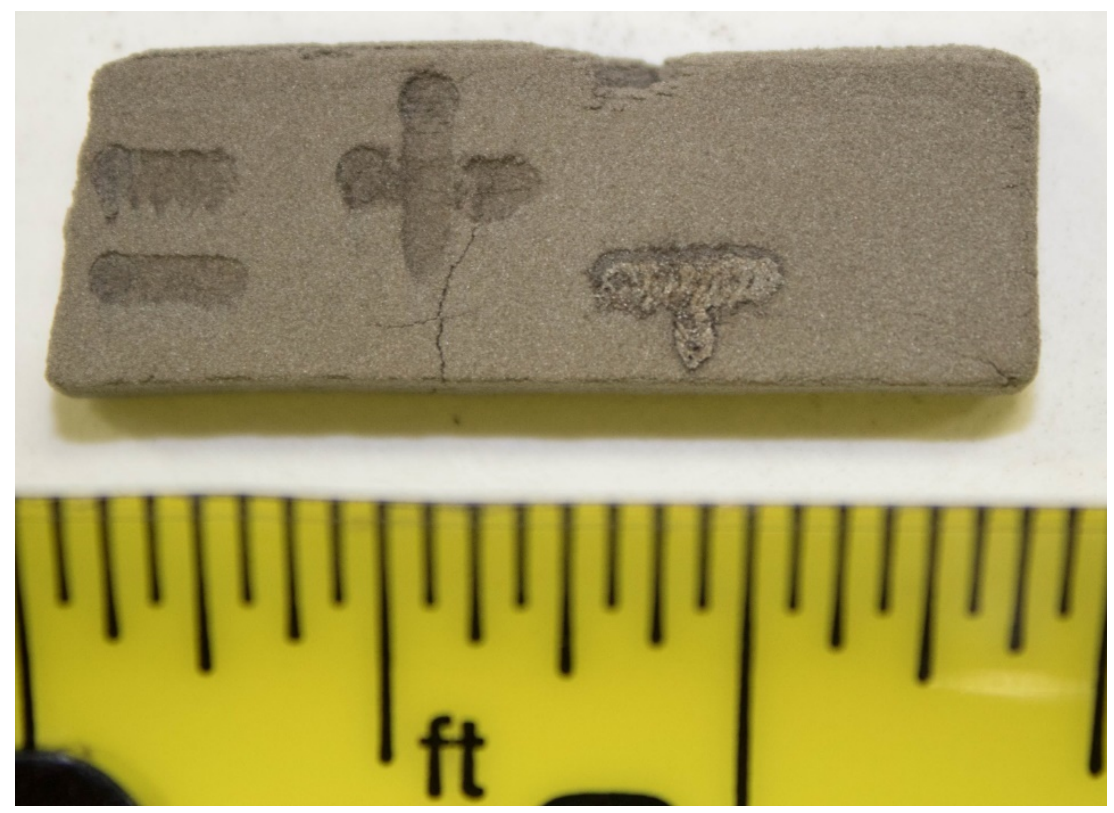

Figure 20. Cross shape built horizontal line first. The upper half of the vertical line didn't sinter due to interference from the horizontal line.

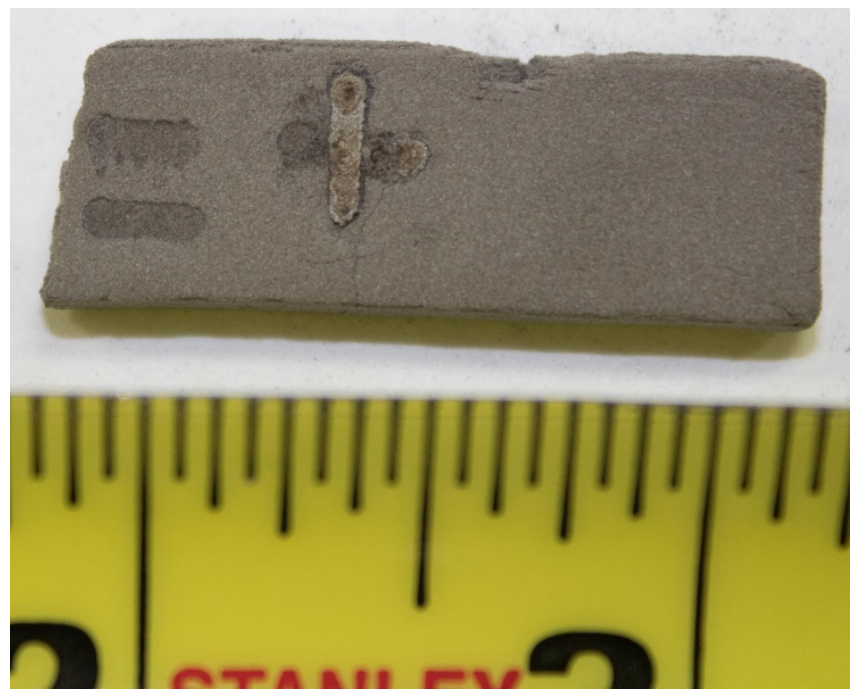

Figure 21. Cross shape built vertical line first. The horizontal line didn't fully sinter due to interference from the vertical line.

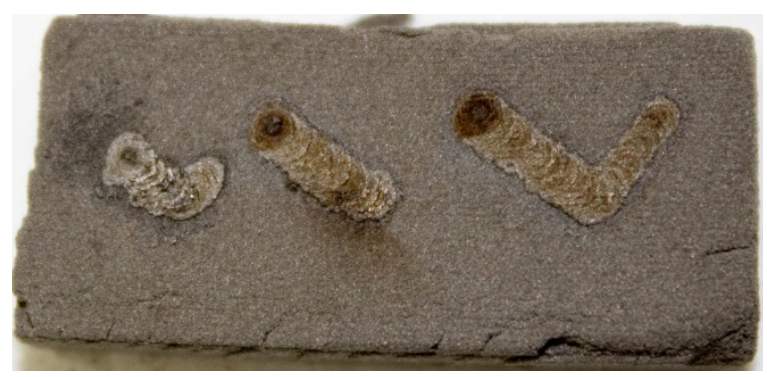

Figure 22. Zig-zag shape built with an upward move direction in the vertical sections. The vertical sections didn't fully sinter due to interference from previously sintered spots. 


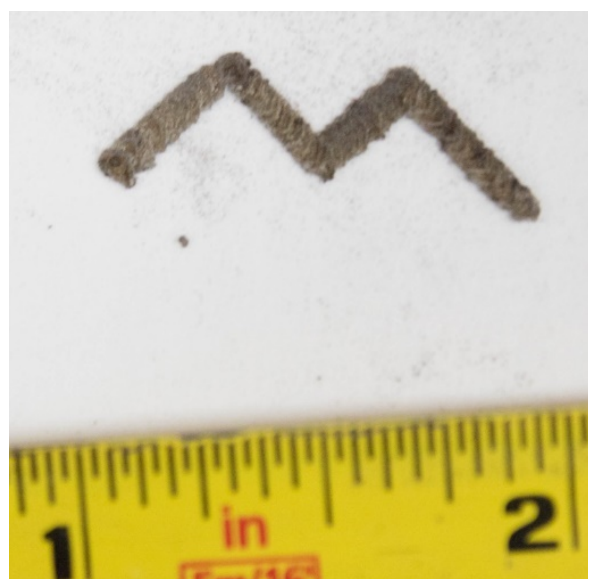

Figure 23. Zig-zag shape built with a downward move direction in the vertical sections.

It was discovered that any lines sintered in the $\mathrm{Y}$ direction must be done with negative move directions. If done in the positive direction, previously sintered dots will overlap the slot in the emitter interfering with the sintering process. Lines in the $\mathrm{X}$ direction can be sintered with either positive or negative move directions as neither will cause previously sintered dots to overlap the slot in the emitter.

Flat rectangular plates were sintered one horizontal line at a time. The resulting parts were quite porous, as is expected with any sintering process (Fig. 24).

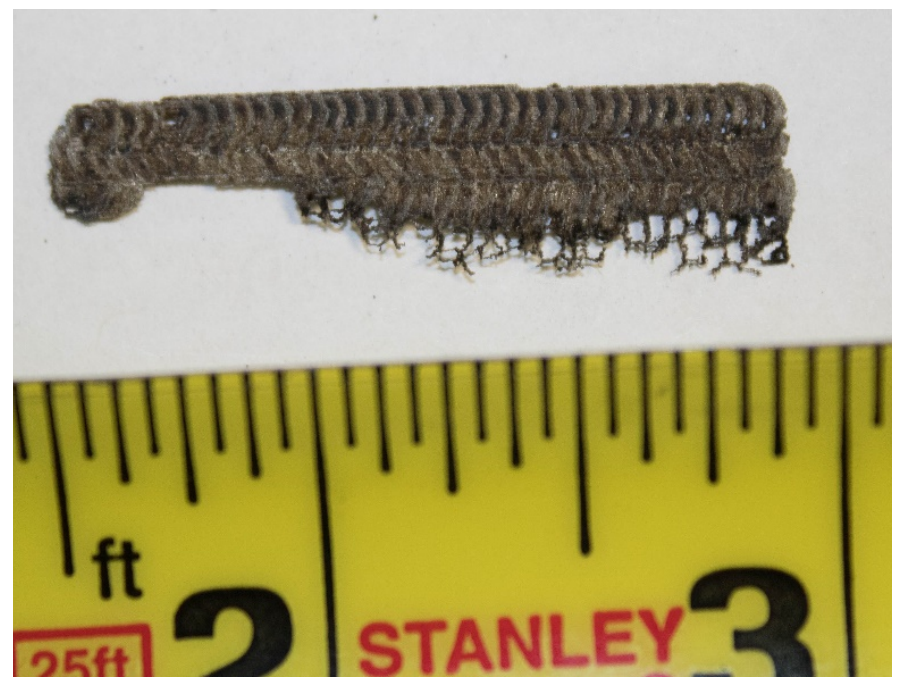

Figure 24. Sintered plate.

\subsubsection{Infiltration of Sintered Parts}

Infiltration with bronze was attempted on one of the sintered SS420 plates in attempt to make a stronger, fully dense part (Figures 25 and 26). While partial infiltration was achieved, the bronze didn't wick properly causing the infiltration to fail. 

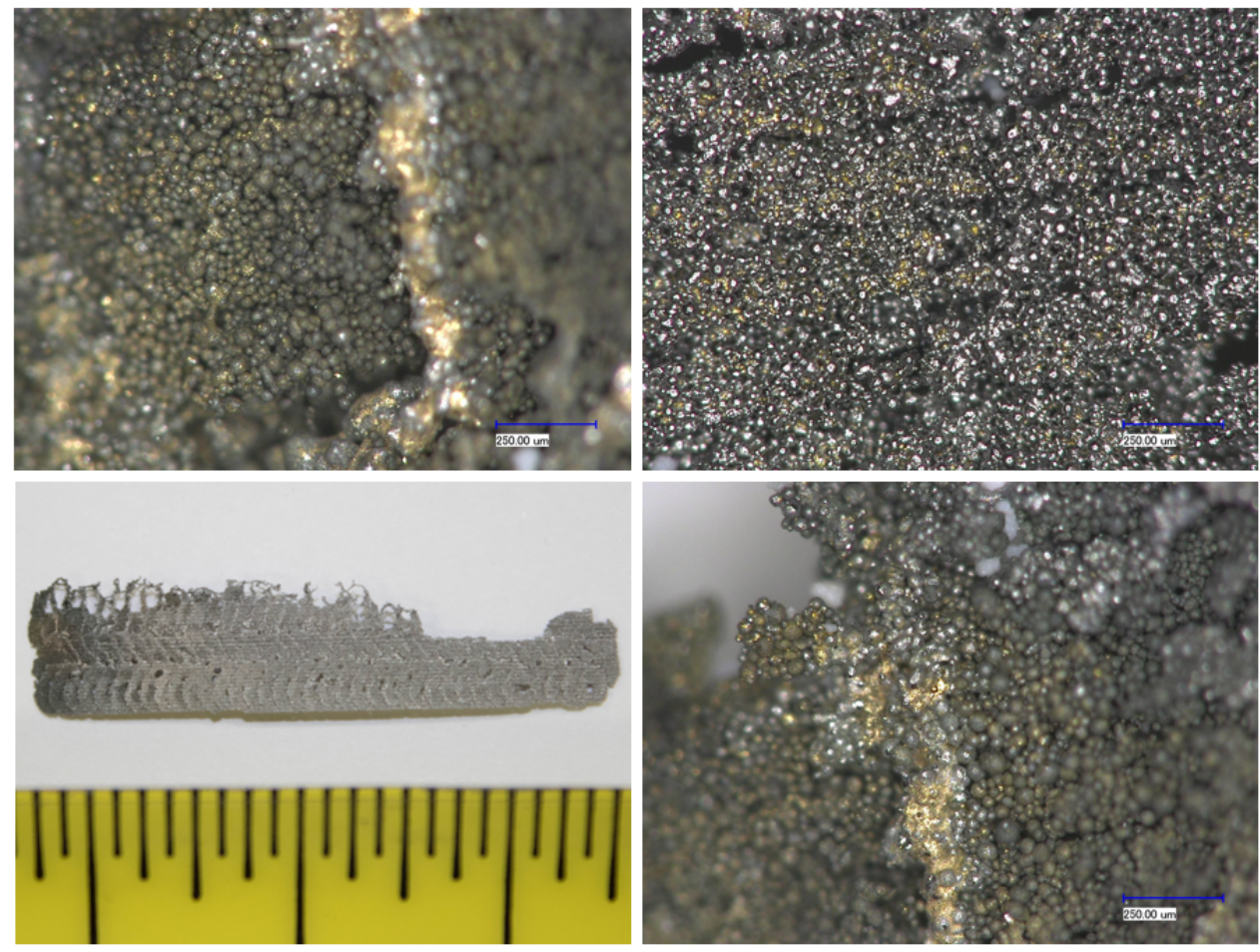

Figure 25. Images of sintered plate after attempted infiltration.
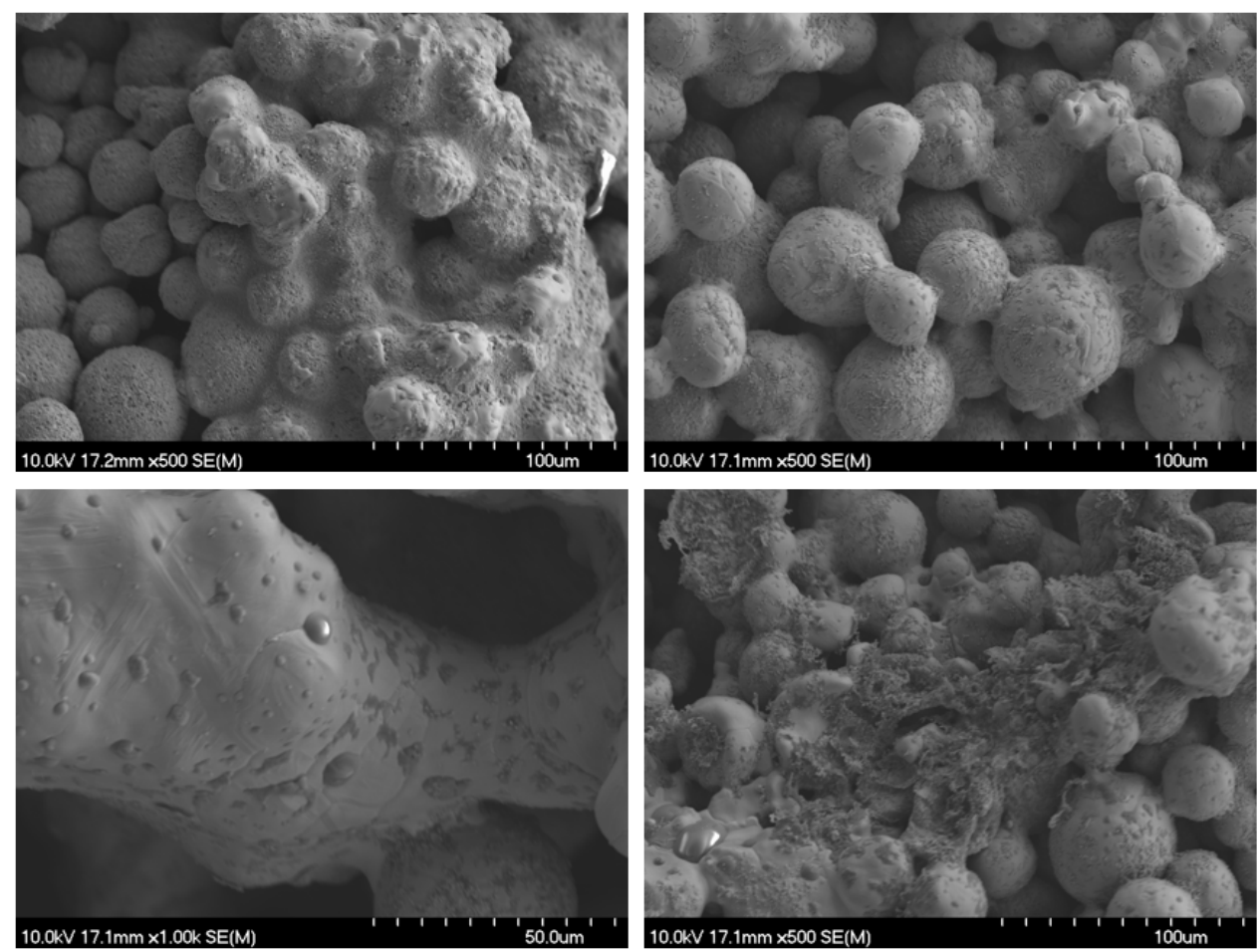

Figure 26. SEM images of sintered plate after attempted infiltration.

\subsubsection{Micro-Induction Sintering of steel powders bound by binder jetted polymer coatings}

In testing it was shown that the same work head that could sinter polymer bound powder 
wouldn't sinter unbound powder. This effect of narrow tuning can be taken advantage of by combining MIS and binder jet systems. The combination of the two systems would allow for the creation of finished parts ready for infiltration, without the need for additional debinding and sintering steps.

First a layer of powder would be spread over the powder bed. Next the binder jet system would deposit binder in the locations required by the part. After the binder is deposited the MIS head would sweep the layer, debinding and sintering the powder only where the binder has been deposited leaving the rest of the layer untouched. This would be done without the need to target specific areas as the work head would be tuned to only couple to the bound powder. A new layer of powder would be spread over the bed and the process repeated until the part was completed (Fig. 27). This part could then be infiltrated with additional metals to create a fully dense part.

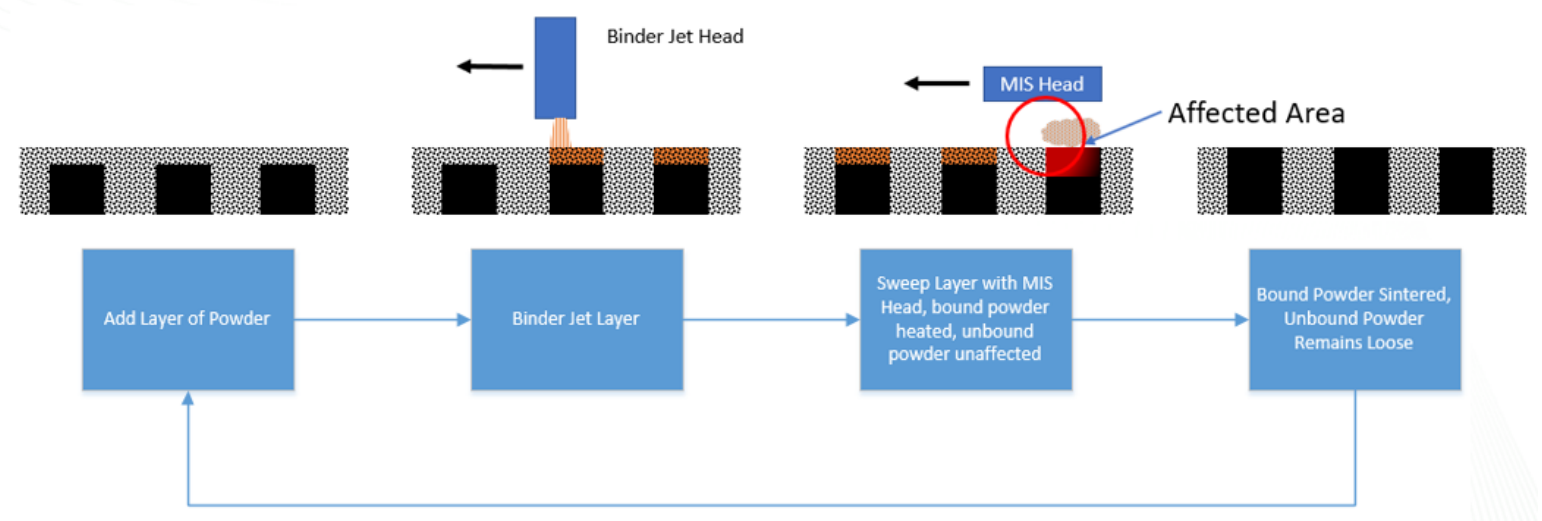

Figure 27. Hybrid MIS-Binder Jet process.

\subsubsection{Mechanism of Operation for Sintering of Bound Powders}

XRD analysis shows a body centered cubic (BCC) structure in the unsintered SS420 powder and a face centered cubic (FCC) structure in the sintered powder (Fig. 27). Analysis of the skin depth using the equation,

$$
\delta=\sqrt{\frac{2 \rho}{\omega \mu_{r} \mu_{0}}}
$$

where $\delta$ is the skin depth, $\rho$ is the resistivity, $\omega$ is the angular frequency, $\mu_{\mathrm{r}}$ is the relative permeability of the material, and $\mu_{0}$ is the permeability of free space $\left(1.257 \times 10-6 \mathrm{~N} / \mathrm{A}^{2}\right)$, shows that the skin depth of the FCC structure is higher than that of the BCC structure. This is taken advantage of by the system as the particles are electrically isolated from each other by the binder requiring a smaller skin depth, then come in contact with each other as they are heated and the binder is decomposed. Due to $\mathrm{RF}$ only heating the surface of the material, a larger skin depth is required in order to maintain a large heated volume. The MIS heating process not only decomposes the binder and sinters the powder, it also changes the structure of the powder from BCC to FCC increasing the skin depth and allowing for a larger heated volume as the particles touch each other creating a larger mass (Figures 28-30). 


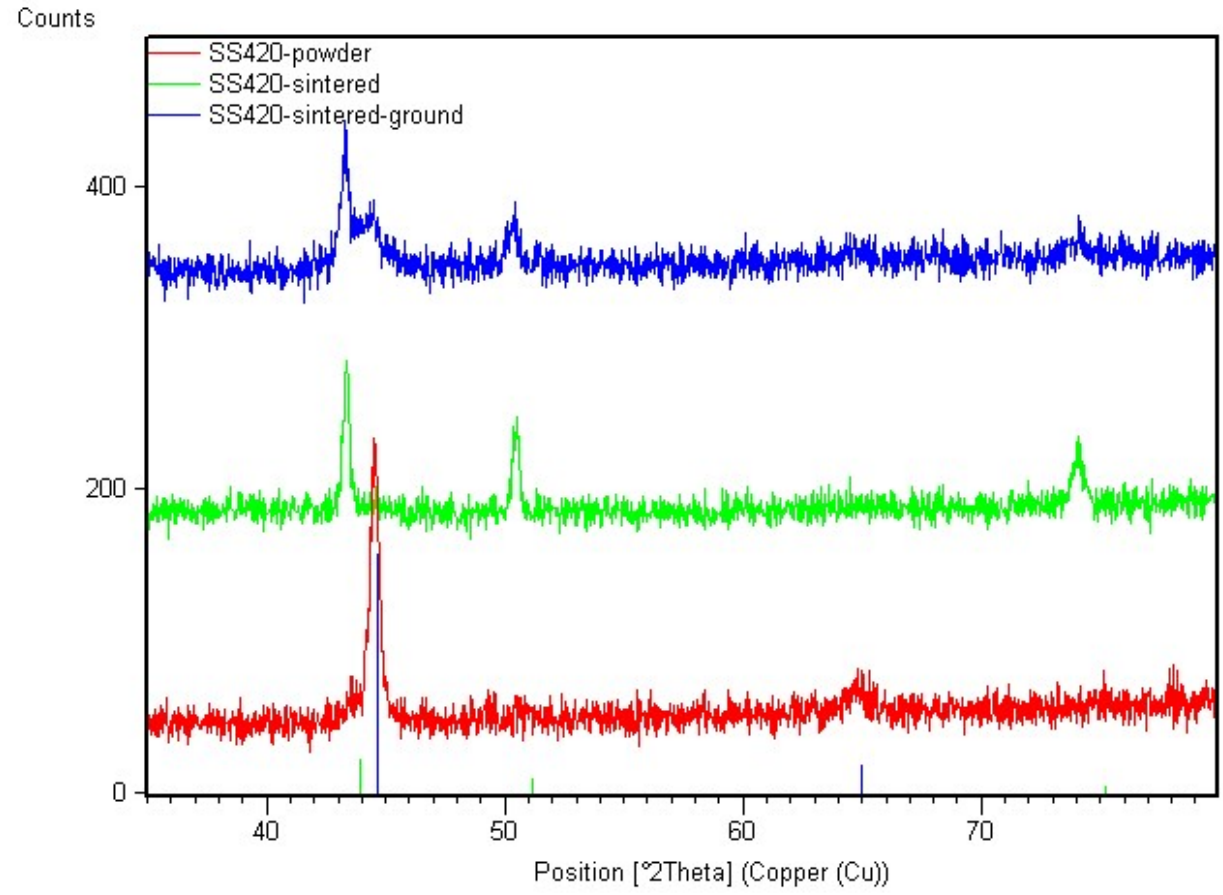

Figure 28. XRD data showing BCC structure for loose powder, FCC structure for sintered powder, and a combination of the two for a ground up piece of a sintered sample.

Individual particles electrically isolated by binder Heating occurs Individually

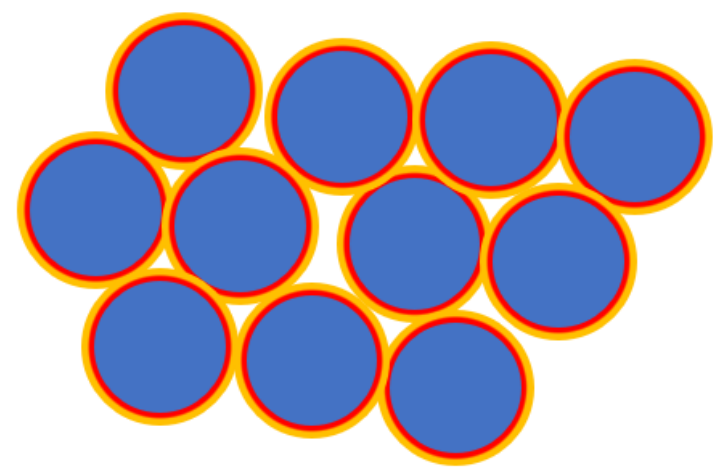

Particles no longer electrically isolated Heating occurs as a mass

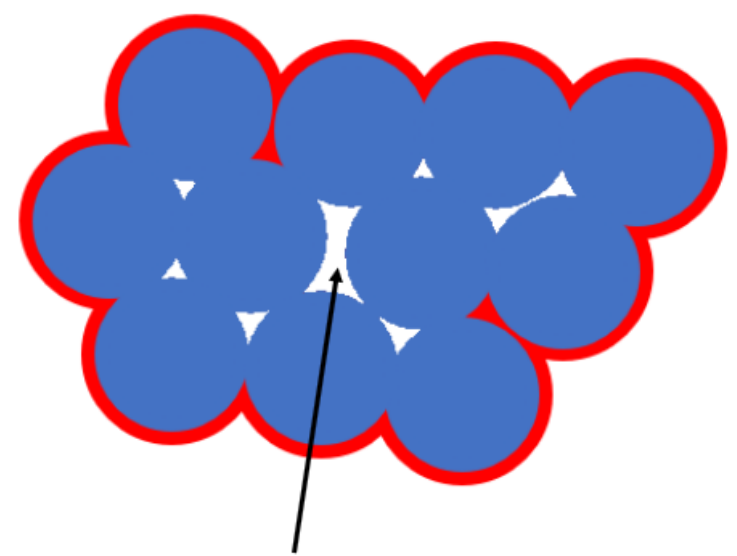

Inner areas shielded from RF

Figure 29. The polymer binder keeps the individual particles electrically isolated from one another, this isolation disappears when the binder is decomposed and the particles start heating as a mass rather than individually. 


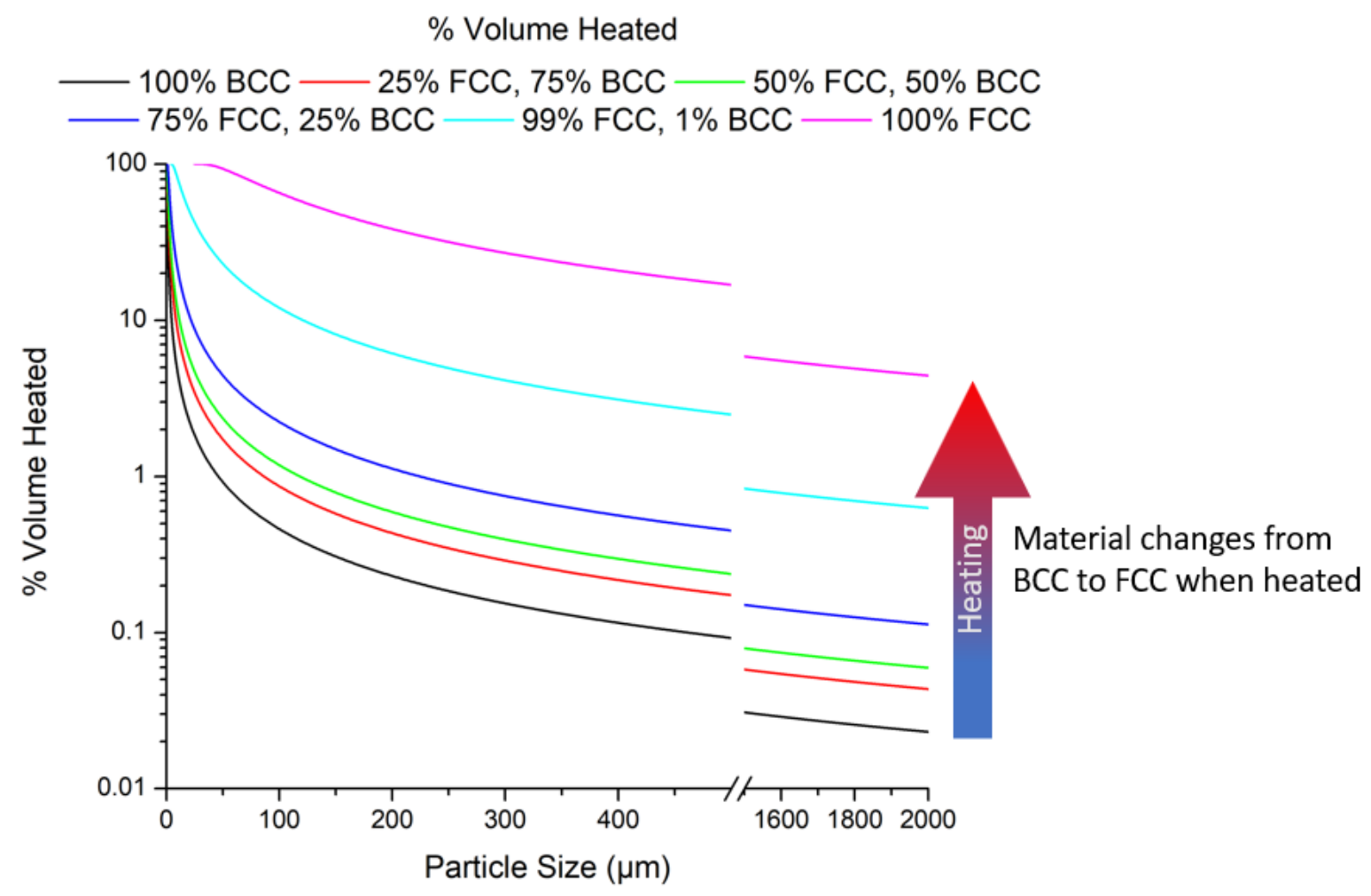

Figure 30. As the material changes from BCC to FCC during heating the skin depth increases. This larger skin depth allows for a larger percentage of the overall mass to be heated.

\subsubsection{Proof of Concept of Selective Sintering}

A proof of concept part was manufactured to show the selective sintering effect (Fig. 31). The part consisted of grid and fin patterns of various sizes. The part was binder jetted and the loose powder was left in the part to simulate a powder layer containing both bound and unbound powder.

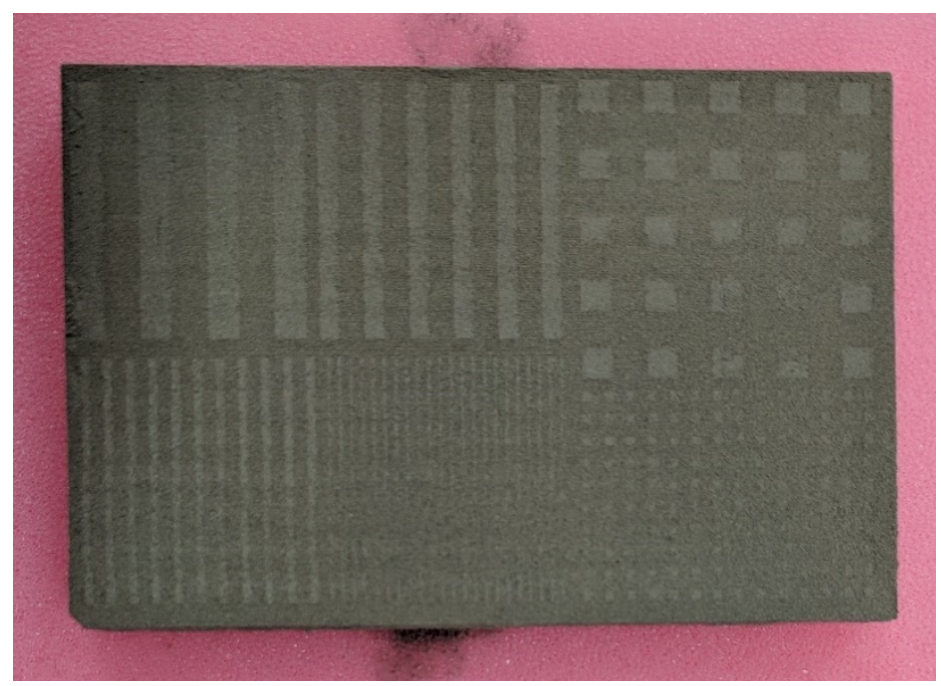

Figure 31. Proof of concept part designed to simulate the hybrid MIS-Binder Jet process. 
The MIS head was used to sinter lines over the part and it was shown that in most cases the bound powder sintered while the loose powder did not (Figures 32 and 33). Due to interference with some of the loose powder, some arcing occurred that resulted in sintering of small portions of loose powder. Arcing was also seen when trying to sinter some of the finer detailed patterns. This arcing could be prevented with further tuning of the work head to allow for a larger gap between the part and the emitter. This proves the concept of using MIS and Binder Jet in a hybrid system as well as demonstrates the ability of the system to achieve higher resolution and smaller feature sizes than MIS alone.

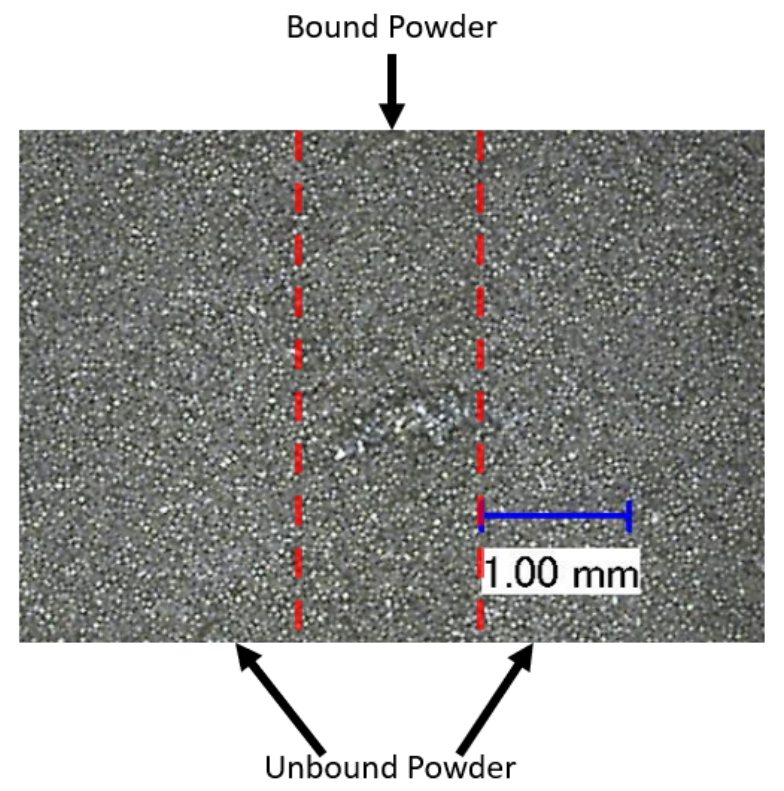

Figure 32. Proof of concept test result.

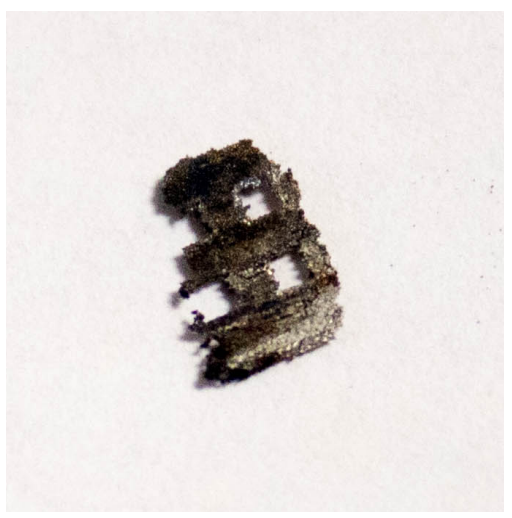

Figure 33. Sintered part showing fine detail captured where there was a lack of bound powder.

\subsection{IMPACTS}

This program created a foundation for Grid Logic's commercial offering of a new class of industrial AM systems and AM production services for large metallic parts. This collaboration enables Grid Logic to make a significant advance in the additive manufacturing industry that will improve its competitiveness and help US manufacturers produce large metallic parts with efficiencies that cannot be accomplished today. 


\subsubsection{Subject Inventions}

Invention disclosure 201804102, titled "Hybrid Micro Induction Sintering System", covering hybrid additive manufacturing systems including an MIS component was filed and a patent will be pursued.

\subsection{CONCLUSIONS}

Micro induction sintering was successfully used to heat and loosely sinter low-cost, water atomized metal powders. The addition of a polymer binder to lock the particles in place improved the process. Higher cost, gas atomized powders further improved these results. The potential for a hybrid system combining other additive manufacturing processes with MIS in order to reduce post processing by taking advantage of MIS's ability to selectively couple with material was demonstrated. Future work could further expand on the sintering ability of MIS allowing for the use of more powders and binders as well as develop hybrid additive manufacturing systems using the MIS process. 


\subsection{REFERENCES}

1. https://www.commscope.com/Blog/Back-to-Basics-in-Microwave-Systems-ReturnLoss-and-VSWR/ 


\section{GRID LOGIC INC. BACKGROUND}

Grid Logic develops advanced manufacturing systems. They build customized solutions for industrial additive manufacturing, inspection, and materials processing. They specialize in solutions for metal and advanced material component fabrication. Industrial companies and government agencies work with Grid Logic to develop new manufacturing capabilities or enhance existing production lines. They provide low-rate production services for custom applications, prototyping, replacement parts, and manufacturing trials. 